NBER WORKING PAPER SERIES

\title{
THE ELASTICITY OF SUBSTITUTION BETWEEN TIME AND MARKET GOODS: EVIDENCE FROM THE GREAT RECESSION
}

\author{
Aviv Nevo \\ Arlene Wong \\ Working Paper 21318 \\ http://www.nber.org/papers/w21318
NATIONAL BUREAU OF ECONOMIC RESEARCH
1050 Massachusetts Avenue
Cambridge, MA 02138 \\ July 2015
}

We thank David Berger, Ariel Burstein, Matthias Doepke, Laura Doval, Martin Eichenbaum, Yana Gallen, Nir Jaimovich, Guido Lorenzoni, Tiago Pires, and Giorgio Primiceri for useful comments. This research was funded by a cooperative agreement between the USDA/ERS and Northwestern University, but the views expressed herein are those of the authors and do not necessarily reflect the views of the U.S. Department of Agriculture or the National Bureau of Economic Research.

NBER working papers are circulated for discussion and comment purposes. They have not been peerreviewed or been subject to the review by the NBER Board of Directors that accompanies official NBER publications.

(C) 2015 by Aviv Nevo and Arlene Wong. All rights reserved. Short sections of text, not to exceed two paragraphs, may be quoted without explicit permission provided that full credit, including $(\mathbb{C}$ notice, is given to the source. 
The Elasticity of Substitution Between Time and Market Goods: Evidence from the Great Recession

Aviv Nevo and Arlene Wong

NBER Working Paper No. 21318

July 2015

JEL No. D12,E31,J22

\begin{abstract}
We document a change in household shopping behavior during the Great Recession. Households purchased more on sale, larger sizes and generic products, increased coupon usage, and shopping at discount stores. We estimate that the returns to these shopping activities declined during the recession and therefore this behavior implies a signicant decrease in households' opportunity cost of time. Using the estimated cost of time and time use data, we estimate a high elasticity of substitution between market expenditure and time spent on non-market work. We nd that households smooth a sizable fraction of consumption by varying their time allocation during recessions.
\end{abstract}

\author{
Aviv Nevo \\ Department of Economics \\ Northwestern University \\ 2001 Sheridan Road \\ Evanston, IL 60208-2600 \\ and NBER \\ nevo@northwestern.edu \\ Arlene Wong \\ Department of Economics \\ Northwestern University \\ 2001 Sheridan Road \\ Evanston, IL 60208-2600 \\ arlene.wong@u.northwestern.edu
}




\section{Introduction}

During recessions, some consumers are faced with lower wealth and declines in income but have more free time. One way to deal with these is to spend more time on non-market work, such as home production and shopping. For example, consumers can lower their expenditure by buying during sales, using coupons, substituting to cheaper brands, buying in bulk, and shopping at discount stores. All of these activities can reduce food expenditures, but require more shopping time and effort. In this paper, we show that indeed consumers changed their shopping behavior during the Great Recession. We then estimate the change in the returns to these behaviors and compute the implied substitution between time and goods expenditure in home production. Finally, we ask to what extent are households able to smooth consumption relative to market expenditures by varying their time use during recessions? Our estimates are important for interpreting the co-movement of aggregate variables over the business cycle, and for computing the welfare costs of recessions.

An important component of many macroeconomic models is how individuals substitute between time and market goods. For instance, Benhabib, Rogerson and Wright (1991) and Greenwood and Hercowitz (1991) propose home production models that incorporate substitution between market and non-market work. In these models, the co-movement between expenditure and employment over the business cycle depends on the willingness of households to substitute between market work, non-market work, and expenditure. However, most estimates of the elasticity of substitution used in these models are based on data from nonrecession periods. It is possible that, like returns to market work, the returns to non-market work also change during recessions.

Aguiar, Hurst and Karabarbounis (2013), a notable exception to the above mentioned studies, use the American Time Use Survey to show that households reallocated lost labor market hours towards non-market work, including shopping, during the Great Recession. Our first contribution in this paper is to examine how this reallocation of time actually translates to lower prices. We use data from the Nielsen Homescan dataset to document how households changed their shopping intensity. The households in our data record their food purchases, the prices paid, and when and where the product was purchased. Each household is in the data set for several years. In total, we have 112,837 households documenting their food purchases from 2004 to 2010.

We document changes in shopping behavior across five key activities during the recent 
recession: purchases of sale items, coupon usage, buying generic products and large sized items, and shopping at discount (Big Box). While past studies have focused on purchases of sale items and store-switching, ${ }^{1}$ we show that adjustments to other shopping activities (using coupons, buying generic and large sized items) also rose noticeably during the recession, and are therefore important for the measurement of inflation and consumption. In fact, all activities rose as a share of total household expenditure during 2008-2010 compared to prerecession trends. The increase is more pronounced in regions that experienced a larger rise in unemployment, suggesting that the rise in shopping intensity is cyclical. We find that the increase in shopping intensity is pervasive across various household demographics, including age, income, and employment status.

Next we ask whether the rise in shopping intensity is driven by an increase in the returns to shopping. For each household, we compute the ratio of the price they paid for the basket of goods purchased, and the cost of the same basket if "average" market prices were paid instead. We then regress this ratio on shopping intensity in our five different activities to measure the returns to shopping, controlling for omitted variables in a couple of ways. We find that these shopping activities lower the price paid by households - for example, consumers who use more coupons pay a lower price. However, we find that the return to shopping declined during the recent recession, even as shopping intensity increased. Our preferred estimates suggest that in 2008-2010 relative to 2004-2007, the returns were around 1-2 percentage points lower for purchases of sale items, using a coupon, buying generic products, purchasing large sized items, and shopping at Big Box stores.

The increase in shopping intensity, coupled with the decrease in returns to shopping, implies a decline in households' opportunity cost of time. This motivates the last step of our analysis, where we use data on prices and quantities to estimate parameters of a home production function. Using a home production model, we recover households' cost of time, and the elasticity of substitution between time and market goods. Specifically, we exploit the fact that at the optimum, households equate the marginal return from shopping to their opportunity cost of time.

We estimate that households' opportunity cost of time declined by 14-26 percent over 2008-2010. The decline in cost of time is consistent with the increase in time spent on non-market work during recessions, which has been documented using time use data in Aguiar, Hurst and Karabarbounis (2013). Using the estimated opportunity cost of time and

\footnotetext{
${ }^{1}$ See for example Coibion, Gorodnichenko and Hong (2012) and Kaplan and Menzio (2014).
} 
price data, we recover a point estimate of 1.7 for the elasticity of substitution between time and market goods in home production, with a standard error of 0.5. This implies a high elasticity of substitution between the home sector and the market sector, which is supportive of parameters used in existing home production models. ${ }^{2}$

Our estimated home production function allows us to address two key questions related to the recent recession. First, we ask whether shocks to the non-market sector were important drivers of the decline in aggregate expenditure and increase in time spent on non-market work over 2008-2010. Answering this question matters for understanding the propagation mechanisms behind the recent recession. We find that the elasticity between expenditure on market goods and time spent on home production is not statistically different between the pre-recession and recession periods, which implies that the recession was not driven by shocks to the non-market sector.

Second, we use our estimated home production function to examine the ability of households to smooth consumption over time by varying their time allocation. While existing studies focus on consumption smoothing via formal and informal mechanisms, in this paper we document the importance of a different mechanism: that is, the intra-temporal allocation of time towards non-market work. ${ }^{3}$ Our contribution is to show that intra-temporal allocation of time is as important for consumption smoothing as other more standard forms of smoothing in the face of large wealth and income declines. Specifically, we estimate that consumption declined by 60 percent less than the fall in market expenditure due to increased home production and time spent shopping during the recession. Our findings complement a recent study by Stroebel and Vavra (2015) who document large responses in shopping activity and prices paid to shifts in household wealth. However, they focus on the implications for firm price setting, while we analyze measurement of household consumption.

Our work contributes to various strands of the literature. First, our work relates to recent studies that use the American Time Use Survey to understand how the allocation of time evolves over the business cycle. Aguiar, Hurst and Karabarbounis (2013), for instance, have shown that roughly 30 percent of the lost labor hours are reallocated towards non-market

${ }^{2}$ See for example, Benhabib, Rogerson and Wright (1991), Greenwood and Hercowitz (1991), Chang and Schorfheide (2003), and Aguiar and Hurst (2007).

${ }^{3}$ Examples of formal mechanisms to smooth consumption include savings, private and public insurance. An example of an informal consumption smoothing mechanism is the labor supply of the second worker in the family. See for example, Kaplan (2012), Blundell, Pistaferri and Saporta-Eksten (2012), and Heathcote, Storesletten and Violante (2009). 
work. Our work provides a natural extension of these studies by explicitly quantifying the extent of consumption smoothing that arises from the time reallocation, and the implied decline in the opportunity cost of time and returns to shopping.

Our work also relates to a growing literature that examines behavior in general, and shopping behavior specifically, during the Great Recession. For example, Coibion, Gorodnichenko and Hong (2012) and Kaplan and Menzio (2014) study shopping behavior and prices during the Great Recession. Their focus, is primarily on search across stores, while we study shopping behavior more broadly. Griffith, OConnell and Smith (2014) look at shopping behavior in the UK during the great recession but focus primarily on the calorie and nutritional implications.

This paper also contributes towards the literature on inflation. For instance, Shapiro and Wilcox (1996) and the Boskin Commission report (1996) show that store-substitution can cause biases in the measurement of consumer inflation, while Griffith et al. (2009) documents the reduction in effective prices paid from a range of shopping activities which may not be fully reflected in a fixed-weight inflation index. More recently, studies such as Chevalier and Kashyap (2011) and Coibion, Gorodnichenko and Hong (2012) show that the gap between effective prices paid and posted prices can vary over time as households change their shopping effort. A recent study by Beraja, Hurst and Ospina (2015) also documents that weaker labor markets in the U.S. experienced lower price growth during the recent recession. We differ from these studies by considering the effect of a broader set of shopping activities.

The rest of the paper is organized as follows. In Section 2, we describe our data and in Section 3, we display trends in shopping characteristics over the cycle. In Section 4, we present our estimates of the returns to shopping during the recent recession. In Section 5, we present a formal home production model and use it to derive the estimation strategy for two key model parameters: 1) the price of time, and 2) the elasticity of substitution between market goods and home production. In Section 6, we provide evidence of robustness of our findings under a range of alternative assumptions. We conclude in Section 7. 


\section{Data and Variable Definitions}

The data we use comes from the Nielsen Homescan database. ${ }^{4}$ The dataset includes information on all food purchased and brought into the home by a large number of households over 2004-2010 from 52 geographically dispersed markets (each roughly corresponding to a Metropolitan Statistical Area) and nine regional areas. Households in the sample are recruited by Nielsen via mail and online. Nielsen offers incentives to households to join and remain active in reporting transactions. These incentives include monthly prize drawings, gift points and sweepstakes. To ensure the quality of data, Nielsen filters out households who do not regularly report their transactions, and regularly adds new households to the panel to replace households who leave the sample. In doing so, Nielsen maintains a national representative sample.

Participating households record the data using hand-held scanners at home. The households record the store where the product was purchased, the date and quantity purchased at the Universal Product Code (UPC) level. For each UPC, the data contains information on the product characteristics, including brand, size and packaging. Prices come from one of two sources. If the store where the product was purchased is one that reports prices to Nielsen as part of their store-level survey, then Nielsen obtains the price from the store data. Nielsen also reports the price paid which can include panelist-reported prices or Nielsenascribed prices if the panelist does not, or is not required to, enter a price. In addition, households record whether the purchased item involved one of four types of deals: (i) store feature, (ii) store coupon, (iii) manufacturer coupon, (iv) any other deal. In the cases where a coupon was used, the household records its value. ${ }^{5}$

Our version of the Nielsen Homescan data has approximately 325 million household purchase transactions over 2004 to 2010, where a transaction is defined at a UPC level. In total, we use data from 112,907 households who report purchases for at least 10 months. These households on average report data over 32 consecutive months. The dataset contains demographic information about the household panelist, which are updated annually. These

\footnotetext{
${ }^{4}$ The data were purchased by the USDA and used as part of a cooperative agreement between the USDA/ERS and Northwestern University. Similar data are available for academic research from the KiltsNielsen Data Center. See http://research.chicagobooth.edu/marketing/databases for details.

${ }^{5}$ One concern with self-reported data is that the data may be recorded with error. However, Einav, Leibtag and Nevo (2010) compare the self-reported data in Homescan with data from cash registers and conclude that the reporting error is of similar magnitude to that found in commonly used economic data sets.
} 
include information on the head(s) of household's age, sex, race, education, occupation, region of residency, employment status, family composition and household income.

We focus on five aspects of shopping behavior: purchases of sale items, coupon use, buying generic products, purchases of large size items (which are typically cheaper per ounce), and shopping at discount (Big Box) stores. These five activities are defined as follows.

Sale An item is defined as being on sale if the household recorded that the item purchased involved a deal.

Coupon Use An item is defined as involving coupon usage if the household recorded that item purchased involved using either a store coupon or a manufacturer coupon.

Generic Product An item is identified as a 'generic product' based on the brand code associated with the UPC.

Large Size Items To define large sized items, we follow Griffith et al. (2009) and rank by size all UPCs in our data within a narrowly defined category. An item is defined as 'large' if the size of the item is in the upper two quantiles of this distribution, i.e., in the top 40 percent of UPCs in the category, ranked by product size.

Big Box store purchase The data identifies the retailer channel that the item was purchased from. Big Box stores are identified as mass merchandise stores, super-centers, and club stores.

For each of these measures, we define shopping intensity as the fraction of household expenditure in each month that comes from each activity. For example, when looking at coupons, we ask in each month what fraction of purchases were made with a coupon. We then seasonally adjust the data at a monthly level. For robustness, we also examined the fraction of purchases and find qualitatively similar results in terms of trends reported in the following section.

Starting in 2007 and continuing to 2008-09, Nielsen introduced a new method of capturing deals on newer devices given to incoming panelists. We verify in two ways that our findings are not affected by this change. First, we include household fixed effects in all of our 
calculations. Since the change only affects new panelists that join after 2006, the household fixed effect captures any differences causes by the new methodology. Second, we redid our analysis with only the consumers that were already in the sample prior to 2007, and hence were unaffected by the change in methodology. We find similar results to our calculations that use the entire sample and include household fixed effects.

\section{Change in Shopping Patterns Over the Cycle}

We start by examining shopping patterns. We focus on the five aspects of shopping behavior defined in the previous section: purchases of sale items, coupon use, buying generic products, purchasing large size items, and shopping at Big Box stores. We document the fraction of expenditure involving various shopping activities and show how the patterns changed during the Great Recession.

To aid in presentation, we display our results graphically. ${ }^{6}$ We report three types of results in the figures below. In all cases, we regress the seasonally-adjusted fraction of overall expenditure for each shopping activity by each household in each month on a household fixed effect (to control for differences across households) and a time trend. We examine three different time trends. First, we describe the data non-parametrically, i.e., we allow for month-year fixed effects. The coefficients on the month-year effects give a non-parametric estimate of the average fraction of expenditure per the month accounted for by the particular shopping activity. To highlight the trend over the sample period, we also calculate cubic and linear spline trends. The cubic trend is estimated from a regression with a cubic trend, instead of month-year fixed effects. The linear spline series is estimated using two break points: the first in December 2007, at the official start of the Great Recession as dated by the NBER; and the second in June 2009, at the end of the NBER recession date.

Figures 2-5 display estimates of the fraction of household expenditures which involve purchases of sale items, coupon usage, buying generic items, buying large-sized items, and shopping at Big Box stores, respectively. The behaviors for sales, coupons, generic and large-sized items, displayed in Figures 2-4, follow similar patterns. Prior to the recession, purchases of items on sale, coupon usage, purchases of generic products, and purchases of large items were either stable or declining as a share of total expenditure. This contrasts

\footnotetext{
${ }^{6}$ To avoid clutter in the graphs, we do not present confidence intervals around the estimates. Given the large number of observations the confidence intervals are small and are available upon request.
} 


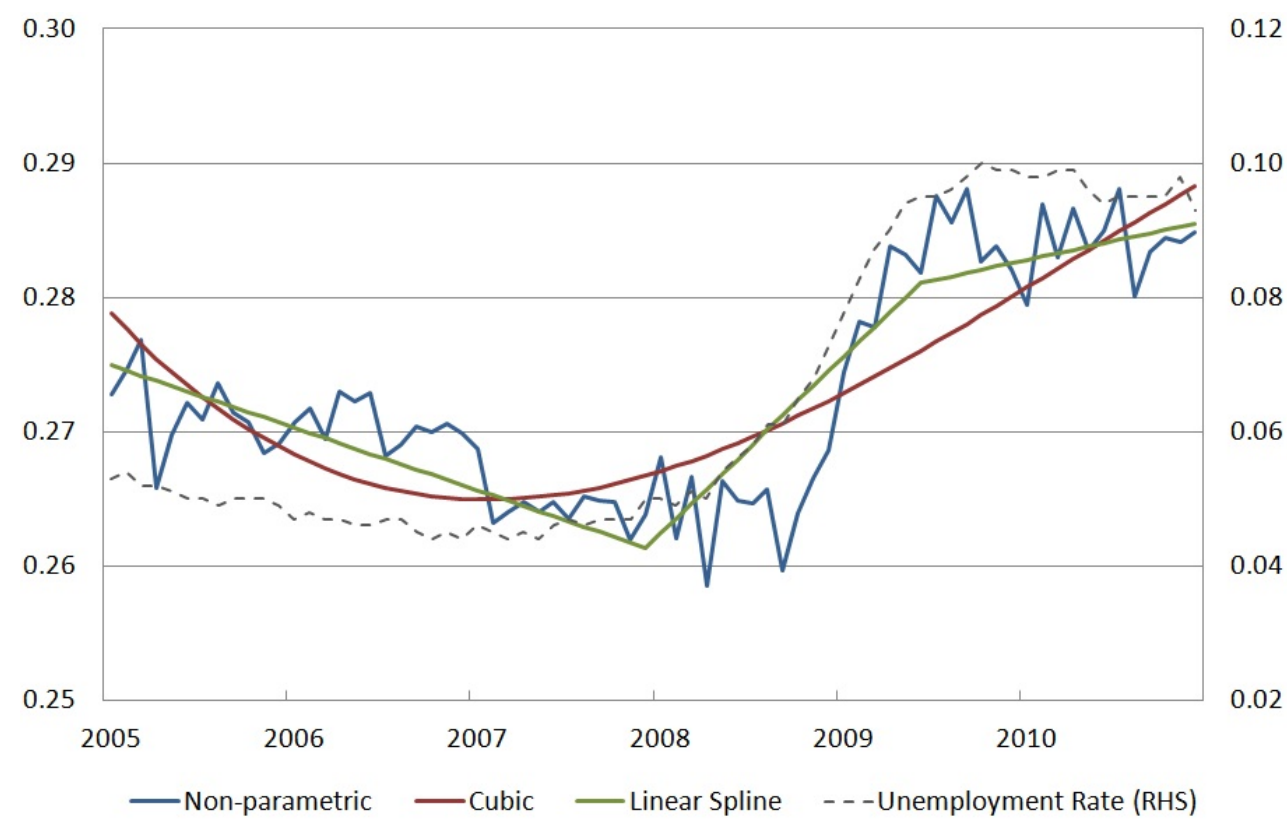

Figure 1: Purchases of Sale Items (Fraction of household expenditure)

with a distinct increase in each of these shopping activities during the recession. Over the recession, these shopping activities each increased by 1.5-2.0 percentage points of total household expenditure. The breaks in the trend are statistically significant and are reported in the first panel of Table 1. These trends closely follow the movement in the aggregate unemployment rate (dashed line in Figures 2-4).

On the other hand, expenditure at Big Box stores, displayed in Figure 5, exhibits a somewhat different pattern. In the pre-recession period, the share of expenditure made at Big Box stores was rising, in large part due to the expansion and growth of Wal-Mart. During 2008-2010, the fraction of expenditure in Big Box stores continued to rise, although at a slower rate than the pre-recession period. As we show in Appendix A Figure 7, the same pattern is observed if we look at other measures of store search intensity, such as the share of expenditure in the household's main store (ranked by spending in that store), their top two stores, their top three stores, and a Herfindahl index of household expenditure by store. Consistent with Kaplan and Menzio (2014), our measures of store search intensity show that households consolidated their search within a smaller number of stores during the recession, which included the Big Box stores.

The increase in shopping intensity during the recession observed in the graphs may reflect business cycle variation, but may also reflect low-frequency structural changes. The 


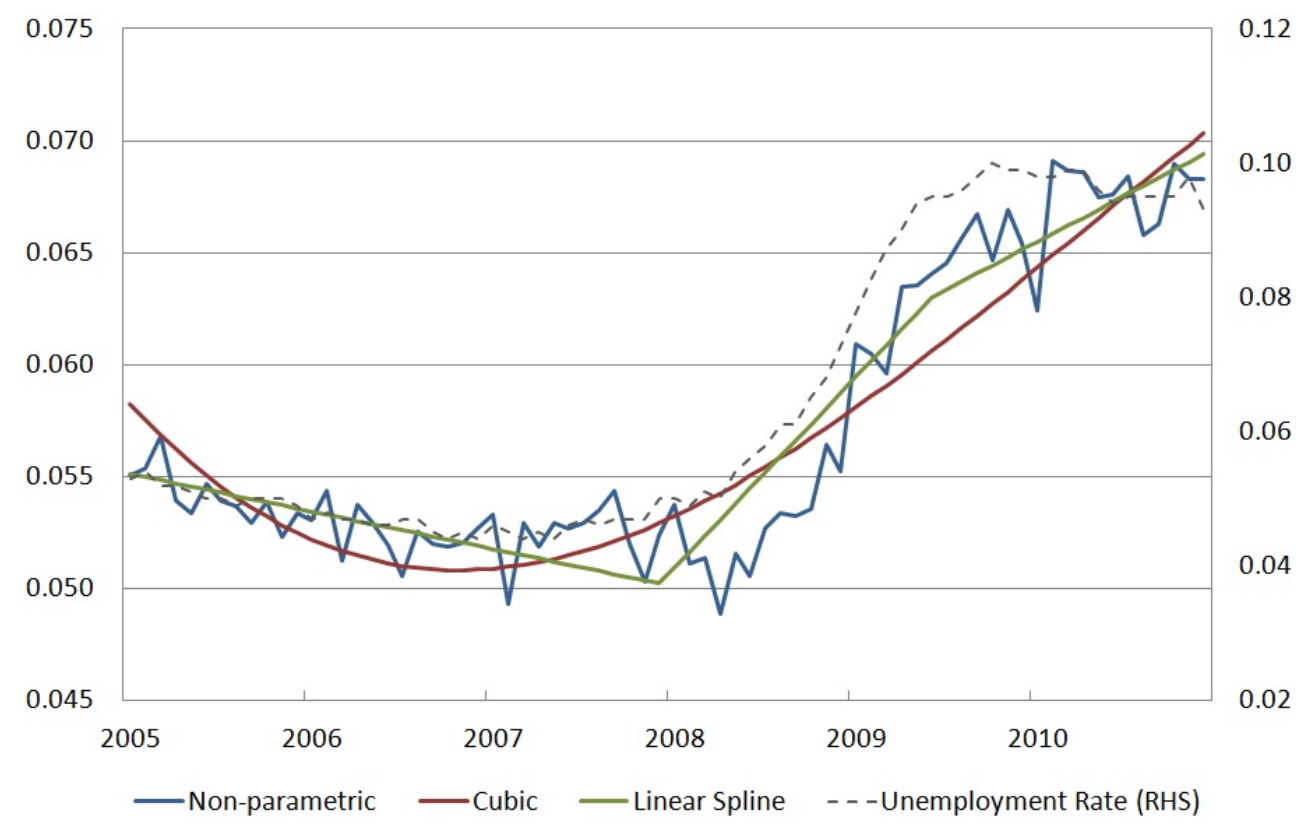

Figure 2: Purchases Involving Coupon Usage (Fraction of household expenditure)

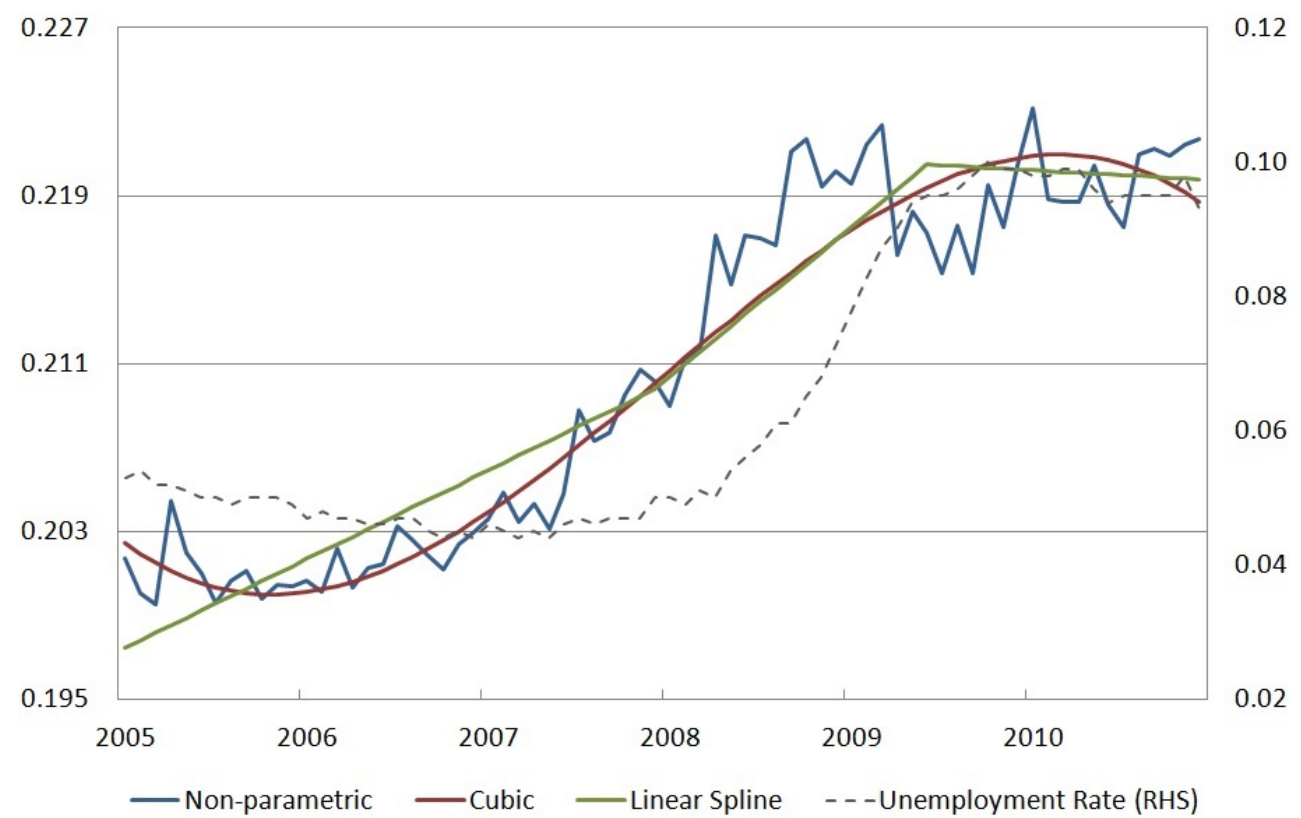

Figure 3: Purchases of Generic Items (Fraction of household expenditure) 


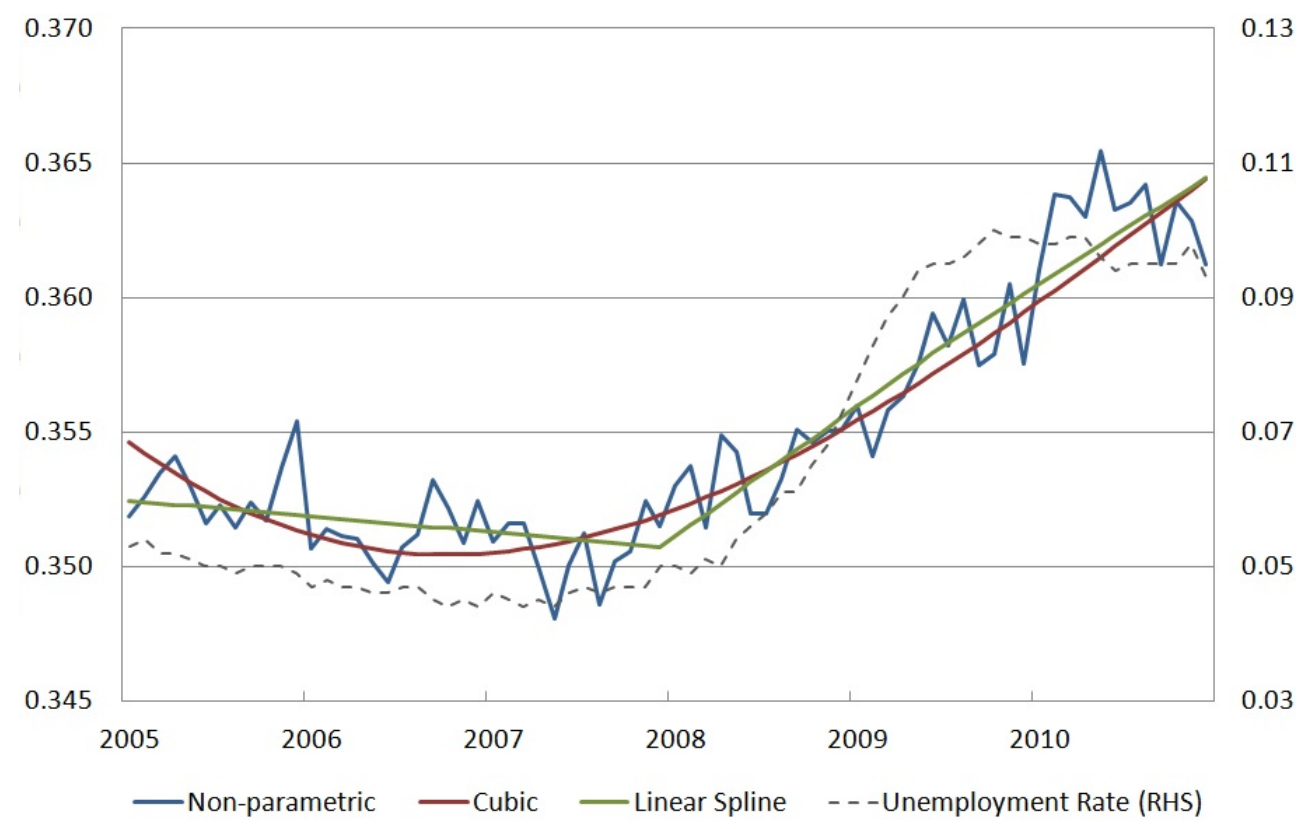

Figure 4: Purchases of Large Sized Items (Fraction of household expenditure)

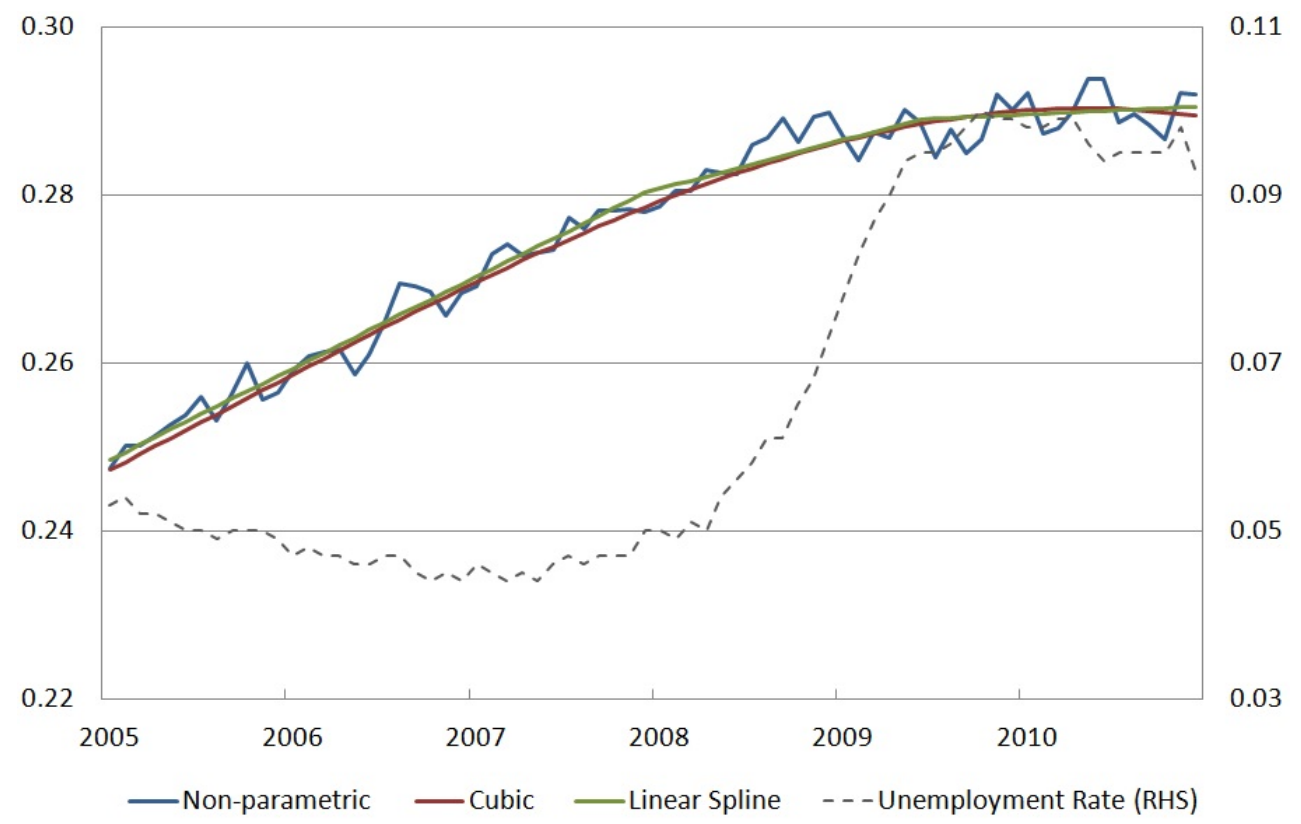

Figure 5: Purchases in Big Box Stores (Share of total household expenditure) 
prevalence of structural trends is particularly relevant for the shopping patterns at Big Box stores, where the trend may reflect the pre-recession expansion of Wal-Mart and its subsequent slow-down in new store openings. The short time frame of our data prevents us from using standard statistical methods to detrend the time series data to examine the business cycle variation. Therefore to isolate the low frequency trends from potential business cyclical variation, we further examine county-level variation in shopping patterns. Using variation across counties allows us to control for common low-frequency trends. We then relate the county-level shopping patterns with local employment conditions to examine business cycle patterns, as it is a measure that is closely correlated with aggregate output during the Great Recession. ${ }^{7}$ Specifically, we estimate for each shopping activity the following equation:

$$
y_{i t}^{k}=\alpha_{0}^{k}+\alpha_{1}^{k} U R_{c(i) t}+\alpha_{2}^{k} t+\alpha_{3}^{k} t \cdot \lambda_{2007}+\alpha_{4}^{k} t \cdot \lambda_{2009}+\lambda_{2007}+\lambda_{2009}+\lambda_{i}+\epsilon_{i t}^{k}
$$

where $y_{i t}^{k}$ is the seasonally-adjusted average fraction of expenditure for household $i$ in month $t$ from shopping activity $k$, and $U R_{c(i) t}^{k}$ denotes the unemployment rate in county $c(i)$ where household $i$ resides. As in Figures 2-5, the regression specification includes linear splines with two breaks (at December 2007 and June 2009) to control for possible linear low-frequency trends that may be occurring over the recession period. This is given by the interaction of the trend $t$ with indicator functions $\lambda_{2007}$ and $\lambda_{2009}$, which equal 1 if $t$ is after December 2007 and after June 2009, respectively. We also control for household fixed effects, denoted by $\lambda_{i}$ respectively; and $\epsilon_{i t}^{k}$ is the random error term.

The coefficients for the time trend terms are statistically significant and reported in the first panel of Table 1 . The second panel of Table 1 displays the coefficients for the linear splines and for unemployment. The patterns in the trend coefficients are very similar to the results in the first panel, which do not control for the county-level unemployment rate. The coefficients on unemployment are positive and statistically significant for each of the shopping activities. This implies that counties that experienced a greater rise in unemployment also on average had more pronounced increases in shopping activities. For instance, the unemployment rate coefficient in column (I) implies that a one percentage point increase in the unemployment rate increases the fraction of expenditure purchased on sale by 11.37 basis points. The positive correlation with the level of unemployment suggests that

\footnotetext{
${ }^{7}$ The approach of using geographic variation to identify changes in household behavior related to the business cycle has also been used in recent studies including Aguiar, Hurst and Karabarbounis (2013) and Mian and Sufi (2010).
} 
Table 1: Cyclical Changes in Shopping Activities

\begin{tabular}{|c|c|c|c|c|c|}
\hline Linear Spline Regressions & $\begin{array}{l}\text { Sales } \\
\text { (I) }\end{array}$ & $\begin{array}{c}\text { Coupon Use } \\
\text { (II) }\end{array}$ & $\begin{array}{c}\text { Generic Item } \\
\text { (III) }\end{array}$ & $\begin{array}{l}\text { Large Size } \\
\quad(\mathrm{IV})\end{array}$ & $\begin{array}{c}\text { Big Box Stores } \\
(\mathrm{V})\end{array}$ \\
\hline time trend & $\begin{array}{l}-2.87 \\
(0.11)\end{array}$ & $\begin{array}{l}-0.71 \\
(0.06)\end{array}$ & $\begin{array}{c}2.56 \\
(0.08)\end{array}$ & $\begin{array}{r}-0.69 \\
(0.1)\end{array}$ & $\begin{array}{c}8.88 \\
(0.15)\end{array}$ \\
\hline time trend $\cdot 1($ post Dec 2007) & $\begin{array}{c}14.8 \\
(0.27)\end{array}$ & $\begin{array}{c}8.99 \\
(0.14)\end{array}$ & $\begin{array}{c}2.34 \\
(0.21)\end{array}$ & $\begin{array}{c}3.67 \\
(0.25)\end{array}$ & $\begin{array}{l}-3.43 \\
(0.38)\end{array}$ \\
\hline time trend $\cdot 1$ (post June 2009) & $\begin{array}{l}-12.79 \\
(0.37)\end{array}$ & $\begin{array}{l}-6.37 \\
(0.19)\end{array}$ & $\begin{array}{l}-2.24 \\
(0.28)\end{array}$ & $\begin{array}{c}0.26 \\
(0.34)\end{array}$ & $\begin{array}{l}-2.98 \\
(0.52)\end{array}$ \\
\hline Cross-county Regressions & $\begin{array}{l}\text { Sales } \\
(\mathrm{I})\end{array}$ & $\begin{array}{c}\text { Coupon Use } \\
\text { (II) }\end{array}$ & $\begin{array}{c}\text { Generic Item } \\
\text { (III) }\end{array}$ & $\begin{array}{l}\text { Large Size } \\
\quad(\mathrm{IV})\end{array}$ & $\begin{array}{c}\text { Big Box Stores } \\
\text { (V) }\end{array}$ \\
\hline time trend & $\begin{array}{l}-2.61 \\
(0.11)\end{array}$ & $\begin{array}{l}-0.71 \\
(0.06)\end{array}$ & $\begin{array}{c}2.65 \\
(0.08)\end{array}$ & $\begin{array}{l}-0.63 \\
(0.10)\end{array}$ & $\begin{array}{c}8.95 \\
(0.15)\end{array}$ \\
\hline time trend $\cdot 1($ post Dec 2007) & $\begin{array}{l}11.29 \\
(0.34)\end{array}$ & $\begin{array}{c}8.88 \\
(0.18)\end{array}$ & $\begin{array}{c}1.24 \\
(0.27)\end{array}$ & $\begin{array}{c}2.97 \\
(0.32)\end{array}$ & $\begin{array}{l}-4.70 \\
(0.49)\end{array}$ \\
\hline time trend $\cdot 1$ (post June 2009) & $\begin{array}{l}-9.20 \\
(0.43)\end{array}$ & $\begin{array}{l}-6.26 \\
(0.22)\end{array}$ & $\begin{array}{l}-1.13 \\
(0.33)\end{array}$ & $\begin{array}{c}0.96 \\
(0.40)\end{array}$ & $\begin{array}{l}-1.66 \\
(0.60)\end{array}$ \\
\hline County unemployment rate & $\begin{array}{l}11.37 \\
(0.68)\end{array}$ & $\begin{array}{c}0.39 \\
(0.36)\end{array}$ & $\begin{array}{c}3.51 \\
(0.53)\end{array}$ & $\begin{array}{c}2.23 \\
(0.63)\end{array}$ & $\begin{array}{c}4.10 \\
(0.96)\end{array}$ \\
\hline
\end{tabular}

Note: For ease of readability, the time-trend coefficients and standard errors (in parentheses) are multiplied by 10,000 . Note, the unemployment coefficients are not multiplied by 10,000 . The coefficients on the unemployment rate variable gives the basis point change in the share of expenditure with the shopping characteristic (for example, buying on sales) given a 1 percentage point change in the unemployment rate. Columns (I)-(V) of the first segment of the table shows estimates from regressing the fraction of each activity on a linear spline with breaks at Dec-2007 and June-2009, controlling for household fixed effects. Each column corresponds to a different regression, varying by shopping activity. These estimates underlie the linear spline line for Figures 1-5. The second segment of the table shows estimates from the regressions of equation (1). These regressions include household and county fixed effects, which are not reported in the table. In total, there are 3,580,610 household-month observations. 
the shift in shopping patterns over 2008-2010, which we observed in Figures 2-4, are indeed related to business cycle factors. ${ }^{8}$

We note that the coefficient on the unemployment rate for the regression of shopping at Big Box stores (column V) is positive and statistically significant, consistent with the other shopping activities (columns I-IV). This implies that there does indeed exist a correlation between declines in economic activity and shopping at Big Box stores, even though this is difficult to see graphically in Figure 5 since the graph also captures low-frequency structural trends.

We also directly estimated the change in each of the shopping activities upon unemployment. Specifically, we regressed the shopping activities on an indicator variable which equals one if the consumer was "non-employed". We exclude those households aged over 65 , to focus those who are likely still in the labor force. We include household and time fixed effects. Consistent with the cross-county regressions, we find that the coefficient on the "non-employed" indicator variable for each of the activities is positive and statistically significant for buying on sale, coupon usage, purchasing generic items and shopping at Big Box stores.

\section{Change in the Returns to Shopping}

In the previous section, we documented that the fraction of expenditure from different shopping activities increased during the Great Recession. In this section, we estimate the change, if any, in the return to these shopping activities. We follow the approach of Aguiar and Hurst (2007) and compute for each household, in each month, the ratio of actual expenditure to the expenditure for the same basket had the household paid average prices. As we describe below, we compute average prices in a variety of ways. We then regress this price index of sorts on measures of shopping activity, as well as other controls such as household fixed effects. We, therefore, are asking how much did a consumer save by shopping, and more importantly did the saving, or return, change during the Great Recession. ${ }^{9}$

\footnotetext{
${ }^{8}$ Our results are consistent with Aguiar, Hurst and Karabarbounis (2013), who use data from the American Time Use Survey to show that households increased their time spent on non-market work, including shopping, during the recent recession. A recent study by Stroebel and Vavra (2015) also show a correlation between house prices and shopping activities.

${ }^{9}$ An alternative approach, used by Griffith et al. (2009), is to regress transaction-level prices, rather than a monthly price index, on the shopping activity. The theory we present below is that of an aggregated
} 
Before discussing the details of implementation we want to highlight a couple of key challenges we face in this exercise: (i) controlling for quality changes, and (ii) interpreting the coefficients as returns to shopping. We describe briefly each of these issues and how we address them in our estimation.

There are two somewhat separate issues in controlling for quality differences. First, when we compute the "average price" a consumer would have paid, we want to make sure we are controlling for quality differences. For example, a consumer might pay less but buy a lower quality good (say a generic product versus a branded product). We address this issue by computing the average price over a variety of product definitions. A narrower product definition might better control for quality, but risks missing avenues of potential savings. Broader product groupings will capture substitution across a wider array of items, but may potentially overstate quality-adjusted price savings if the items within the group differ in quality. The product definitions we use are discussed in more detail below.

Second, by holding the basket constant, between actual expenditure and expenditure computed using average prices, we potentially face a substitution bias. To address this we repeat the calculations using average market quantity weights, rather than householdspecific quantity weights. As we explain below, since the quantity weights used to compute the price index are not household-specific, any changes over time in the price index for a given household, will not reflect quality differences in their bundle relative to the rest of the market. ${ }^{10}$

A separate issue we need to deal with is the measurement of shopping. In the regressions below we will use the fraction of items bought, say, on sale as a measure of shopping. The issue is that this measure could change even if the shopping activity does not, because of supply side behavior. For example, suppose that firms offer more frequent sales, then even without an increase in shopping intensity the household will buy more on sale and the increase in shopping activity would be overly attributed to greater consumer shopping intensity.

commodity. We therefore need the effects of shopping activities on the price of this aggregate commodity, which is better reflected in the price index specification. In contrast, the transaction-level regression would need to be weighted in order to provide the appropriate results. For example, we may want to give a higher weight to items that account for a larger fraction of a household's expenditure basket. This weight is thus potentially household specific. Coupled with the large size of the data, this quickly becomes intractable.

${ }^{10}$ Note that in a sense, the quality substitution bias that arises is similar to the bias that arises when using Laspeyres indices to measure inflation. 
We address this in a couple of ways. First, we note that the price index we compute directly addresses these concerns since we compare actual expenditure to the expenditure the household would have paid at the average price in the market. Thus, supply-side effects that are common across households within the market are netted out in the price index. Indeed, we show that our results are robust to different market definitions. Second, in the modeling section we show how we can deal with a change in the relationship between our measure of shopping activity and the theoretical shopping intensity.

\section{Price index with household-specific weights}

Denote the price paid for good $j$ (at a UPC level) on shopping trip $t$ by household $h$ as $p_{j, t}^{h}$, and the corresponding quantity as $q_{j, t}^{h}$. We compute a price index by comparing the actual expenditure to the expenditure that the household would have incurred if they had instead paid the average price in the market, denoted by $\bar{p}_{j, m}$ for item $j$ in month $m$.

Specifically, we define a price index for the household in month $m$ as the ratio of their actual expenditure to the cost of the bundle at the average price

$$
\tilde{p}_{m}^{h} \equiv \frac{\sum_{J \in \mathbf{D}} \sum_{j \in \mathbf{J}, t \in m} p_{j, t}^{h} q_{j, t}^{h}}{\sum_{J \in \mathbf{D}} \sum_{j \in \mathbf{J}, t \in m} \bar{p}_{j, m} q_{j, t}^{h}}
$$

where $\mathbf{J}$ denotes the set of all UPCs belonging to product $J$, and $\mathbf{D}$ denotes the set of all products. The index is then normalized by dividing by the average price index across households within the month

$$
p_{m}^{h} \equiv \frac{\tilde{p}_{m}^{h}}{\frac{1}{\tilde{H}_{m}} \sum_{k} \tilde{p}_{m}^{k}}
$$

where $\tilde{H}_{m}$ denotes the total number of households in the sample in month $m$. This ensures that the distribution of price indices across households is centered around 1 each month. An index that is above 1 indicates that household $h$ paid a higher average price for its basket of goods in month $m$, while an index below 1 indicates that a lower average price was paid.

This price index deals with the two issues that we mentioned previously. First, because we use a relative price index we control for shocks that are common across households within the same market. Market-level shocks affect both the individual's expenditure (the numerator of equation 2) as well as the comparison expenditure at average market prices (the denominator of equation 2). In the base analysis, we define the market at a nationallevel. Therefore the average price $\bar{p}_{j, t}$, is computed across all households at time $t$. In the 
Section 6, as robustness, we also consider defining a market at a county-level (hence $\bar{p}_{j, m}$ is computed across all households in the county, excluding the individual $j$ ). We consider the county-level definition to control for the possibility that there may be regional shocks.

To deal with potential differences in quality, the price index compares prices of items within the same product group. To the extent that these items have the same quality, then variations in the relative price index are not driven by quality differences. We consider four different definitions of a product. In this section we define a product as: (i) a UPC, (ii) all items with the same characteristics, or (iii) all items within a product module. In Section 6 , as robustness, we define a product by splitting items within a product-module into two further groupings of branded and generic products.

The first index we compute, as in Aguiar and Hurst (2007), the average price paid by households for a particular UPC $j$

$$
\bar{p}_{j, m} \equiv \sum_{h \in \mathbf{H}, t \in m}\left(\frac{q_{j, t}^{h}}{\sum_{h \in \mathbf{H}_{\mathbf{m}}, t \in m} q_{j, t}^{h}}\right) p_{j, t}^{h}
$$

where $\mathbf{H}_{\mathbf{m}}$ denotes the set of all households in the sample in month $m$. This approach has the advantage of controlling for the quality of the product purchased since it only considers the price paid by other households for the same UPC. However, it does not account for the savings that households can achieve by buying different sizes and different brands. It also does not fully account for potential savings from shopping at Big Box stores since these stores often carry different UPCs. Thus, this index will underestimate the total savings from these shopping activities.

Therefore, we also consider a second index which defines a product as the set of items that have the same characteristics. This controls for shifts in quality by comparing prices of items with common characteristics (and hence of similar quality), while still capturing some price savings that come from substituting across sizes and brands within the same group (as in Kaplan and Menzio (2014)). The intuition behind grouping these items is that they may have different UPCs, but are in fact close substitutes from the perspective of buyers. The features given in the data that we consider for defining a product include: "flavor", "form", "salt content", "type", and "style". This approach is broader than the UPC-specific definition. However, to the extent that items can have different characteristics and similar overall quality, then the index will still understate the quality-adjusted price savings, although to a lesser extent than the UPC-product definition. 
Thus, we consider an even broader product definition using product modules, which allows for substitution among brands as well as different sizes. Specifically, we calculate the average per ounce price paid for item $j$ of size $s_{j}$ by taking the average across all items of the same size belonging to the product category $J$,

$$
\bar{p}_{j, m} / s_{j} \equiv \sum_{k \in \mathbf{J}, h \in \mathbf{H}, t \in m}\left(\frac{q_{k, t}^{h}}{\sum_{k \in \mathbf{J}, h \in \mathbf{H}_{\mathbf{m}}, t \in m} q_{k, t}^{h}}\right) p_{k, t}^{h} / s_{k}
$$

This average price is normalized by dividing by the size of the item to allow for comparison across different sizes.

Defining a product at a product-module has the advantage of allowing for substitution across sizes and brands of a large set of items within the product-module. We note that this approach assumes all items within the product are substitutable and therefore does not consider quality differences across items within the product module. So in a sense, it is the other extreme from the UPC-level index: here we assume all items in a group are perfect substitutes while before we assume they are not substitutes at all.

In Section 6, we consider an alternative index that controls for quality differences between generic and non-generic products, and show that our results are robust to substitution between goods of different quality.

\section{Price index with market weights}

The second way that we control for quality is to consider an alternative relative price index, where every consumer has the same quantity weight that is based on the market average quantity, rather than having a different quantity weight for each individual. Specifically, we consider a second version of the price using average market quantity weights

$$
\tilde{p}_{m}^{h} \equiv \frac{\sum_{J \in \mathbf{D}} \sum_{j \in \mathbf{J}, t \in m} p_{j, t}^{h} \bar{q}_{j, t}}{\sum_{J \in \mathbf{D}} \sum_{j \in \mathbf{J}, t \in m} \bar{p}_{j, m} \bar{q}_{j, t}}
$$

The average market quantity weight is defined as

$$
\bar{q}_{j, t} \equiv \bar{X}_{j t} / \bar{p}_{j, m}
$$

where $\bar{X}_{j t}$ is the average household expenditure on item $j$ in month $t$.

Since quantity weights are the same for all households, any changes over time in this price index for a given household do not reflect changes in their bundle, and hence are not subject to quality bias due to household choices. 


\section{Returns to Shopping}

To estimate the returns to the shopping activities, we regress the price indices we previously described on the fraction of items bought involving each shopping activity. Formally, we estimate the following regression using household monthly observations

$$
\begin{aligned}
\ln p_{m}^{h}= & \alpha_{0}+\delta Z_{m}^{h}+\nu Z_{m}^{h} \cdot \mathbf{1}(\mathrm{yr}>2007)+\lambda_{h} \\
& +\sum_{i} \alpha_{i} f_{i, m}^{h}+\sum_{i} \beta_{i} \mathbf{1}(\mathrm{yr}>2007) \cdot f_{i, m}^{h}+\gamma \mathbf{1}(\mathrm{yr}>2007)+\epsilon_{m}^{h}
\end{aligned}
$$

where $p_{m}^{h}$ is the price index (defined in the previous section) of the basket of goods purchased by household $h$ in month $m ; Z_{m}^{h}$ denotes the vector of household time-varying demographics, including age, employment status, and marital status of the head of household, and household income; and $\lambda_{h}$ controls for household time-invariant fixed effects. Since the regression includes household and recession period fixed effects, the error term in the regression primarily includes random shocks to the relative price paid by the household.

The variable $f_{i, m}^{h}$ denotes the fraction of items in the basket of goods purchased by household $h$ involving shopping activity $i$ (which includes buying on sale, coupon usage, buying large sizes, buying generic products and shopping at Big Box stores) in month $m$. Our focus is on the interaction of these variable with the recession dummy variable $\mathbf{1}(\mathrm{yr}>2007) .{ }^{11}$ The coefficients of interest are $\alpha_{i}$ and $\beta_{i}$, which give the sensitivity of price to each shopping activity before and during the recession. A negative $\alpha_{i}$ implies the shopping activity decreases the price (hence has a positive return), while a positive $\beta_{i}$ implies a decline in returns during the recession.

The first three columns of Table 2 show the regression results for equation (6) using price indices that have household-specific weights. Each column uses a different price index as the dependent variable, where the definition of a product varies across the indices. As discussed above, we provide a range of product definitions to consider possible shifts in quality associated with price savings. Specifically, column (I) is based on the relative price index that defines a product at a UPC-level. Any price differentials are not due to changes in the quality of items purchased by the households, since we compare the price of the same UPC. However, the narrow definition also does not allow for possible substitution across sizes and brands, which is a key way in which consumers reduce prices. To measure the

\footnotetext{
${ }^{11}$ To simplify presentation we do not separate out the post-recession observations (i.e. the observations in year 2010). In Section 6, we show that our findings are robust to excluding the post-recession observations.
} 
importance of substitution across size and brand, Columns (II) and (III) considers broader product definitions. The index in column (II) defines a product based on common item characteristics, while column (III) defines a product at a product-module level.

Our results are qualitatively similar across the three indices. Specifically, we generally find that shopping activities lower the price paid by the household. In the pre-recession period, we estimate that the marginal price paid was reduced by $2-4$ percent by buying on sale, 31-33 percent by using a coupon, and 5-11 percent from shopping at a Big Box store. The results for generic products and larger sizes are a bit different across the columns: the results in Column (I) suggest these activities either do not have a meaningful economic effect on the price paid, while the results in Columns (II) and (III) suggest that prices decreased by 13-25 percent from buying a generic product, and 20-47 percent from buying large-sized items. These differences are not surprising since, as we previously discussed, the first price index essentially shuts down the savings channel created by buying larger sizes or generic products because it compares the price paid for the same UPC. The direction and magnitude of the effects is consistent with those found in the literature. ${ }^{12}$

The second result that we find is that the returns to each of the shopping activities declined over the recession period. Specifically, we estimate that returns were approximately 2 percentage points lower (as seen in the estimated coefficients of the interaction of shopping activity with a dummy for the recession period in Table 2). The estimated decline in returns, coupled with the increase in shopping activities that we documented, implies that the shifts in household shopping activities are associated with changes in their opportunity cost of time, rather than a response to changes made by firms. This therefore motivates the next section, where we use a household home production model to recover the change in the households' opportunity cost of time over the recession.

As we discussed above, one concern is that the estimates of returns may reflect differences in changes in quality across households, or differential county-level supply-side shifts. In Tables 2 (columns IV-VI) and 8 (in the appendix), we show that this is not the case. First, we repeat the analysis using instead price indices that weight the prices paid by consumers using a market-wide quantity weight. That is, we use the same quantity weight per productmonth pair for every consumer in the market. We can see that the results shown in columns (IV-VI) of Table 2 are qualitatively similar to the corresponding columns (I)-(III). Therefore, price differentials over time do not reflect differences in changes to the expenditure bundle

\footnotetext{
${ }^{12}$ See for example, Aguiar and Hurst (2007), Griffith et al. (2009), and Kaplan and Menzio (2013, 2014).
} 
across consumers.

Second, we repeat the analysis specifying a market at a county-level, instead of the entire U.S. market. As we discussed above, we consider the county-level definition of a market to control for the possibility that there may be regional differences in supply-side shifts. Common within-county supply shifts are netted out by comparing the consumer's paid price to the average price paid by consumers within the same county since they affect both the consumer's price and the average price. The results are shown in Table 8 of the appendix. The results are qualitatively similar to U.S-wide market averages (Table 2). These results imply that the declines in returns to shopping are not driven by region-specific supply shocks.

Another potential concern is that the shopping intensity may be measured with error. This could arise if for example there exists unobserved variation in shopping productivity across consumer which varies over time which is correlated with the shopping activities. Therefore, for robustness, we also examined the implied change in cost of time using number of shopping trips as an alternative measure of shopping activity. Formally, we regress the $\log$ of the price indices on the log of the total number of shopping trips in a month, as well as UPC and household fixed effects. Following Aguiar and Hurst (2007), we use age dummies to instrument for measurement issues associated with shopping time. ${ }^{13}$ Consistent with our estimates of the individual shopping activities, we find that the average price paid also declines when shopping trips increase, but that the level of price savings declined during the recession period. Specifically, we estimate that doubling the number of shopping trips reduced prices by 12 percent during the pre-recession period. In comparison, doubling the number of shopping trips reduced prices by 9 percent during the recession period.

To sum up, in this section, we have shown that the price savings from engaging in the individual shopping activities (buying on sale, using coupons, and so forth) declined during the recession period. Moreover, as discussed above, these lower returns are consistent with findings in the literature that retail sales did not become deeper or more frequent during the recession period. Together, these findings imply that the pronounced increase in shopping activity during the recession period, which we documented in the previous section, was not being driven by higher returns to shopping. These findings motivate the next section where

\footnotetext{
${ }^{13}$ As discussed in Aguiar and Hurst (2007), the age dummies are used as instruments for potential measurement error in the shopping trips. These errors could arise, for example, if shopping time is measured with error using the number of shopping trips. The use of age as an instrument is based on the premise that the value of time varies over the life-cycle, which will in turn influence the shopping intensity, as argued in Aguiar and Hurst (2007).
} 
we explore the implications of these shopping activities for measuring households' value of time.

\section{A Model of Home Production}

In this section, we use the implications of the previous results for measuring households' opportunity cost of time during the recent recession. We then recover the elasticity of substitution between time and market goods, a key parameter in the home production literature. To do so, we describe a simple model of household cost minimization. The model is in the spirit of Becker (1965), and subsequent time use and home production papers, including Aguiar and Hurst (2007), Rupert, Rogerson and Wright (1995), Greenwood and Hercowitz (1991) and others. The basic intuition behind these models of home production is that individuals substitute between home produced and market produced goods based on their relative price. Therefore, changes to the price of time and elasticity of substitution can be recovered from changes to the returns to shopping and time use data.

In the previous section, we showed that households can reduce the price they pay by varying the shopping activities of their basket. However, engaging in these shopping activities also has a cost of time for the household. For example, shoppers may spend time searching through newspapers to find coupons for a particular store. They may also spend time driving to multiple stores to find the lowest price for a particular set of goods. This relationship between shopping time and price can be summarized in a price function $p(s, \mathbf{N})$, where $\partial p / \partial s<0$ and $\partial^{2} p / \partial s^{2}>0$. The time spent shopping is denoted by s. Other activities of the shopping basket, not related to shopping time, that may influence price paid are denoted by $\mathbf{N}$. Total expenditure on the quantity $Q$ of market goods purchased is given by

$$
p(s, \mathbf{N}) Q
$$

We assume that the quantity of purchased market goods is converted into a consumption good $C$ using a home production technology $K(h, Q)$. Households combine time $h$ spent on home production with the quantity of market goods $Q$ to produce $C$, which enters the household's utility function. The home production function is assumed to be concave in $h$ and $Q$. Therefore, in addition to the shopping technology, households can also substitute time for expenditures via their home production function. 
Table 2: Estimated Returns to Shopping

\begin{tabular}{|c|c|c|c|c|c|c|}
\hline Variable & Indices witl & household q & antity weights & Indices $\mathrm{w}$ & market qu & tity weights \\
\hline & (I) & (II) & (III) & $(\mathrm{IV})$ & $(\mathrm{V})$ & $(\mathrm{VI})$ \\
\hline Sale & $-3.00 * * *$ & $-1.84^{* * *}$ & $-3.48 * * *$ & $-2.97 * * *$ & $-4.34^{* * *}$ & $-7.20^{* * *}$ \\
\hline & $(0.03)$ & $(0.07)$ & $(0.09)$ & $(0.03)$ & $(0.05)$ & $(0.08)$ \\
\hline Coupon & $-32.70^{* * *}$ & $-32.50 * * *$ & $-31.90^{* * *}$ & $-34.00 * * *$ & $-34.90^{* * *}$ & $-34.00^{* * *}$ \\
\hline & $(0.06)$ & $(0.14)$ & $(0.18)$ & $(0.06)$ & $(0.11)$ & $(0.16)$ \\
\hline Big Box & $-5.27 * * *$ & $-7.98 * * *$ & $-11.10^{* * *}$ & $-5.50 * * *$ & $-7.16^{* * *}$ & $-8.37^{* * *}$ \\
\hline & $(0.02)$ & $(0.05)$ & $(0.07)$ & $(0.02)$ & $(0.04)$ & $(0.06)$ \\
\hline Generic & $-0.71^{* * *}$ & $-13.00^{* * *}$ & $-24.20^{* * *}$ & $-0.91^{* * *}$ & $-14.10^{* * *}$ & $-28.30^{* * *}$ \\
\hline & $(0.04)$ & $(0.09)$ & $(0.11)$ & $(0.04)$ & $(0.06)$ & $(0.1)$ \\
\hline Large size & $0.37^{* * *}$ & $-19.80^{* * *}$ & $-46.70^{* * *}$ & $0.23^{* * *}$ & $-14.60^{* * *}$ & $-39.20^{* * *}$ \\
\hline & $(0.04)$ & $(0.09)$ & $(0.12)$ & $(0.04)$ & $(0.07)$ & $(0.1)$ \\
\hline Sale $1(y r>2007)$ & $0.92 * * *$ & $0.69^{* * *}$ & $0.87^{* * *}$ & $0.88^{* * *}$ & $0.72^{* * *}$ & $1.22 * * *$ \\
\hline & $(0.03)$ & $(0.07)$ & $(0.09)$ & $(0.03)$ & $(0.05)$ & $(0.08)$ \\
\hline Coupon $1(\mathrm{yr}>2007)$ & $0.51^{* * *}$ & $0.68^{* * *}$ & $0.99^{* * *}$ & $0.42^{* * *}$ & $0.33^{* * *}$ & $0.65^{* * *}$ \\
\hline & $(0.07)$ & $(0.15)$ & $(0.19)$ & $(0.07)$ & $(0.11)$ & $(0.17)$ \\
\hline Big Box 1(yr>2007) & $0.30 * * *$ & $1.31^{* * *}$ & $1.82^{* * *}$ & $0.28^{* * *}$ & $0.93^{* * *}$ & $1.39^{* * *}$ \\
\hline & $(0.03)$ & $(0.06)$ & $(0.07)$ & $(0.03)$ & $(0.04)$ & $(0.06)$ \\
\hline Generic $1(\mathrm{yr}>2007)$ & $-0.44^{* * *}$ & $1.13^{* * *}$ & $0.79^{* * *}$ & $-0.46^{* * *}$ & $0.95^{* * *}$ & $0.84^{* * *}$ \\
\hline & $(0.04)$ & $(0.1)$ & $(0.13)$ & $(0.04)$ & $(0.07)$ & $(0.11)$ \\
\hline Large Size $1(y r>2007)$ & -0.06 & -0.06 & $1.26^{* * *}$ & $-0.13^{* * *}$ & $-0.48 * * *$ & 0.09 \\
\hline & $(0.05)$ & $(0.11)$ & $(0.14)$ & $(0.05)$ & $(0.08)$ & $(0.13)$ \\
\hline Product definition & UPC & Features & $\mathrm{PM}$ & UPC & Features & $\mathrm{PM}$ \\
\hline Market definition & U.S. & U.S. & U.S. & U.S. & U.S. & U.S. \\
\hline Index quantity weights & Household & Household & Household & Market & Market & Market \\
\hline $\mathrm{N}$ & $4,243,987$ & $4,243,983$ & $4,243,983$ & $4,243,987$ & $4,243,983$ & $4,243,983$ \\
\hline R-squared & 0.63 & 0.49 & 0.59 & 0.64 & 0.60 & 0.65 \\
\hline
\end{tabular}

Note: This table reports estimates of the regression estimates for equation (6), with different price indices in each column. The coefficients give the percentage point price saving from each of the shopping activities. Standard errors are in parentheses. ${ }^{* *},{ }^{* *},{ }^{*}$ denote significance at a 1,5 , and 10 percent level, respectively. Columns (I)-(III) use price indices with individual household-specific quantity weights, while (IV)-(VI) use the average market quantity weights. The columns also vary in the product definition: (I) and (IV) use the $\log$ Price Index 1, where a product is as a UPC. (II) and (V) use log of Price Index 2, where a product consists of items that have the same features (see text for more detail). (III) and (VI) use the log of Price Index 3, where a product is defined at the product module. Each regression includes household and month fixed effects and time-varying demographics. 
The trade-off between time, market goods, and consumption goods can be summarized in the household's cost minimization problem

$$
\min _{s_{t}, h_{t}, Q_{t}} p\left(s_{t}, \mathbf{N}_{\mathbf{t}}\right) Q_{t}+\mu_{t}\left(s_{t}+h_{t}\right)
$$

subject to

$$
K\left(h_{t}, Q_{t}\right)=C_{t}
$$

where $\mu_{t}$ is the opportunity cost of time in period $t .{ }^{14}$ We consider interior solutions to the problem by making the usual monotonicity and concavity assumptions for the utility, price, and home production functions.

The first-order condition for shopping time is given by

$$
\mu_{t}=-\frac{\partial p_{t}}{\partial s_{t}} Q_{t}
$$

This condition implies that the shopping intensity $s$ increases as the price of time $\mu$ falls, holding the shopping bundle $Q$ fixed. The opportunity cost of time can therefore be recovered from the marginal return to shopping, holding $Q$ fixed.

The first-order condition for home production is

$$
\mu_{t}=\frac{\partial K_{t}}{\partial h_{t}} \lambda_{t}
$$

where $\lambda_{t}$ is the multiplier on the constraint. The first-order condition for $Q_{t}$ is

$$
\lambda_{t} \frac{\partial K_{t}}{\partial Q_{t}}=\frac{\partial p_{t}}{\partial Q_{t}} Q_{t}+p_{t}
$$

where $Q_{t}$ is an element of $\mathbf{N}_{\mathbf{t}}$. Combining with the intra-temporal conditions (8) and (9) gives the marginal rate of transformation between time and market goods in home production

$$
\frac{\partial K_{t} / \partial h_{t}}{\partial K_{t} / \partial Q_{t}}=-\frac{\frac{\partial p_{t}}{\partial s_{t}} Q_{t}}{\frac{\partial p_{t}}{\partial Q_{t}} Q_{t}+p_{t}}
$$

\footnotetext{
${ }^{14}$ Note that the other choices made by the household are reflected in $\mu_{t}$ and $C_{t}$, including decisions about labor supply and inter-temporal allocation of consumption.
} 
Therefore, the first-order conditions from the household's cost minimization problem allows us to recover their opportunity cost of time, and the elasticity of substitution between time and market goods in home production, which we estimate in the following section.

\subsection{Implications for the Opportunity Cost of Time}

Equation (8) implies that the opportunity cost of time can be estimated from the returns to shopping, which can be rewritten as

$$
-\frac{\partial p_{t}}{\partial s_{t}} Q_{t}=-\frac{\partial \ln p_{t}}{\partial s_{t}} \cdot p_{t} Q_{t}=-\frac{\partial \ln p_{t}}{\partial f_{i t}} \cdot \frac{\partial f_{i t}}{\partial s_{t}} \cdot X_{t}
$$

where $s$ denotes the shopping time, $f_{i t}$ denotes the share of items purchased with shopping activity $i$, and $X_{t}=p_{t} Q_{t}$ denotes total expenditure. The empirical counterpart of $p_{t}$ is the composite price index (defined in Section 4) for one real composite food unit $Q$. To allow for comparison across time and across households, the composite food unit $Q$ is empirically constructed as the average market value of goods, deflated by average market inflation

$$
Q_{m}=\sum_{J \in D} \sum_{j \in \mathbf{J}, t \in m} \bar{p}_{j, m} q_{j, t} / \Pi_{t}
$$

where $\mathbf{J}$ denotes the set of all UPCs within $D$, the set of all product categories in the sample. $\bar{p}_{j, m}$ is the expenditure-weighted average price paid for item $j$, where the average is taken across all households who made a purchase of $j$ in month $m$. As described in Section 4, we consider two different average price indices: one defined as the average price at a UPC-level, and the second as the average price over all UPCs within a product category. $\Pi_{t}$ is the BLS inflation index for food.

We have estimates of two of the terms in equation (12): $\partial \ln p_{t} / \partial f_{i t}$ (the sensitivity of price to each shopping activity which was estimated in Section 4), and $X_{t}$ (the expenditure per month from the Homescan data). To recover the cost of time, we also need to know how the shopping activities change when the household engages in an extra unit of shopping time, denoted by $\partial f_{i t} / \partial s_{t}$. We assume that $\partial f_{i t} / \partial s_{t}$ is equal to $\gamma_{i} / f_{i t}$, where $\gamma_{i}$ is a constant parameter that varies with shopping activity $i$. In Section 6 , we show that our results are qualitatively robust to a range of alternative functional form assumptions about $\partial f_{i t} / \partial s_{t}$.

The opportunity cost of time is given by 


$$
\mu_{t}=-\frac{\partial \ln p_{t}}{\partial f_{i t}} \cdot \frac{\gamma_{i}}{f_{i t}} \cdot X_{t}
$$

which is equal for all shopping activities (coupon usage, purchase of sale items, purchase of large items, buying generic products, and shopping at Big Box stores), because at the optimum households equate the marginal return from each shopping activity. Thus, equation (13) can be recovered using the shopping return estimates in Section 4 (Table 2), combined with Homescan data for $X_{t}$ and $f_{i t}$. Note that the scalar term $\gamma_{i}$ drops out when we consider the change in cost of time.

The change in the opportunity cost of time is given by

$$
\triangle \mu_{t+1} \equiv \frac{\mu_{t+1}}{\mu_{t}}=\frac{\partial \ln p_{t+1} / \partial f_{i, t+1}}{\partial \ln p_{t} / \partial f_{i t}} \cdot \frac{f_{i t}}{f_{i, t+1}} \cdot \frac{X_{t+1}}{X_{t}}
$$

We consider the change in the opportunity cost of time over two periods: $t$ denotes the prerecession period of 2004-2007, and $t+1$ denotes the recession period 2008-2010. As discussed above, the returns from each shopping activity imply the same change in opportunity cost of time because at the optimum, households equate the marginal return from each activity. However, suppose we measure the cost of time with some error $\epsilon_{i t}$ for each shopping activity $i$. This implies that we observe

$$
\triangle \mu_{t+1}=\triangle \hat{\mu}_{t+1}+\epsilon_{i, t+1}
$$

where $\triangle \hat{\mu}_{t+1}$ is the actual change in opportunity cost of time. Combining equations (14) and (15), taking logs and rearranging, we have

$$
\ln \left(\frac{\partial \ln p_{i, t+1} / \partial f_{i, t+1}}{\partial \ln p_{i t} / \partial f_{i t}} \cdot \frac{f_{i t}}{f_{i, t+1}}\right)=\beta_{0}+\eta_{i, t+1}
$$

where $\beta_{0}=\left(-\ln X_{t+1} / X_{t}+\ln \Delta \hat{\mu}_{t+1}\right)$ is the constant which can estimated from a regression of equation (16). We can therefore recover the underlying change in cost of time $\triangle \hat{\mu}_{t+1}$ from an estimate of $\beta_{0}$. The error term is denoted by $\eta_{i, t+1}$.

To estimate equation (16), we construct the empirical counter-part of the dependent variable from our estimates of $\partial \ln p_{t} / \partial f_{i t}$ from Table 2 . This is combined with an estimate of the average fraction of expenditure for each shopping activity $i$, denoted $f_{i t}$, where the average is computed from the Homescan data across all households-months within time 
period $t$. To recover the cost of time $\triangle \hat{\mu}$, we also need $-\ln \triangle x_{t+1}$, the log of the change in total expenditure during the recession period. We construct the empirical counter-part for this by taking the log of the average ratio of total expenditure during the recession period relative to total expenditure during the pre-recession period, where the average is computed from the Homescan data across all households in the sample. We compute the standard errors around the opportunity cost of time based on the estimated standard errors of the shopping returns from Table 2 for the coefficients of $\partial \ln p_{i, t} / \partial f_{i, t}$.

Table 3 displays the estimated change in the opportunity cost of time during the recession. The estimates in columns (I)-(III) are based on different estimates of the change in returns to shopping from Section 4, which vary in their definition of a product (Table 2). Column (I) is based on returns estimated from a price index that defines a product as a UPC, (II) defines a product as all items with the same characteristics, and (III) defines a product as an item within a product module. Column (IV) considers the case where we assume no change in returns to shopping - hence, any difference in cost of time is due to changes in shopping activities and expenditure. In Table (3), we observe a decline in the households' opportunity cost of time of 20-26 percent during the recession. The decline in cost of time can be decomposed into three factors (as seen in equation (14)): variation in shopping returns, in shopping activities, and in expenditure.

Even if we assume there is no change in the returns to shopping during the recession, then we would estimate a decline in the opportunity cost of time of 14 percent (Table 3, column II). The reason why the cost of time still declines is because of increases in the shopping activities. This implies that around half of the decline in the overall cost of time was due to changes in shopping activities, while lower returns to shopping accounted for the remaining half.

One potential concern about our measure of the opportunity cost is that the effect of shopping time on returns may be measured with error. First, we note that in the case that the measurement error is not time-varying, the error will affect the level estimate of the cost of time but not the change in the cost of time which is what we are interested in measuring in equation (16). In the case where the measurement error is time-varying, the estimate of the cost of time will potentially be biased. However, we do not find evidence that the measurement error is time-varying. We formally tested for a change in the relationship between shopping activities $f$ and shopping time $s$ during the recession, and find that the 
relationship is stable over the sample period. ${ }^{15}$

Another related concern is that the measured value of time may have changed as a result of the distribution of posted prices faced by households, rather than demand-side shifts in shopping intensity. However, as we discussed in the previous section, our price indices explicitly controls for market supply-side shifts. This is because the relative price index nets out common supply-side shocks since these shocks affect both the consumer's own expenditure as well as the comparison market-average expenditure. Thus, estimated changes in returns using the index, and therefore the measured change in value of time, reflect movements in consumer behavior and not supply-side changes to posted prices.

Our estimated change in opportunity cost of time is for the average consumer. These changes of between 14-26 percent may seem large, but it is worth noting that they are consistent with the sizable declines in household income and wealth during the recent recession. Specifically, real household median income declined by almost 10 percent over 2007-2012, while real median household net wealth declined by 40 percent over 2007-2013 (from the Survey of Consumer Finances). In the face of large declines in wealth, standard incomplete markets models would predict a decline in household consumption. The decline in consumption would be associated with a fall in the value of time for households within the class of utility functions that have non-separable preferences between consumption and leisure. Our results here imply large effects of wealth and income on households' value of leisure and therefore their willingness to work over the business cycle. ${ }^{16}$

\subsection{The Elasticity of Substitution Between Time and Market Goods}

In this section, we use our estimated cost of time to derive the parameters of the home production function, including the elasticity of substitution between time and market goods. Models with home production typically rely on a high elasticity parameter in order to explain a number of business cycle facts, such as the observed level of variation in aggregate output

\footnotetext{
${ }^{15}$ Specifically, we merge on data on shopping-time from the American Time Use Survey, based on household demographics of age, marital status, gender and year. We then regress each of the average shopping activity $f_{i t}$ of demographic group $i$ in month $t$ on the square-root of the shopping time $s_{i t}$ and the interaction with the recession period. We find that the coefficient on the (square-root) shopping time does not change significantly during the recession period for any of the shopping activities. This implies that the relationship is not time-varying over the pre and current recession periods.

${ }^{16}$ Our calculations complement recent studies, such as Stroebel and Vavra (2015), that examine the relationship between price elasticity and wealth.
} 
Table 3: Implied Change in the Opportunity Cost of Time

(2008-2010) vs. (2004-2007)

Change in cost of time

$-0.261$

$(0.003)$

Using estimated returns from: Table 2 (I)

UPC

Product definition

Market definition

U.S.
(II)

$-0.242$

$(0.010)$

Table 2 (II)

Features

U.S.
(III)

$-0.228$

$(0.006)$

Table 2 (III)

$\mathrm{PM}$

U.S.
(IV)

$-0.137$

$(0.000)$

Assuming no

change.

n.a.

n.a.

Note: This table reports the recovered opportunity cost of time, using data on household expenditure, and returns to shopping, estimated in Section 4. Columns IV reports the estimated change in cost of time assuming no change in returns. Standard errors are in parentheses.

and market hours of labor over the business cycle. ${ }^{17}$ For example, Karabarbounis (2014) shows that a model of home production that assumes an elasticity parameter close to 4 can explain the observed variation over the business cycle in the wedge between marginal product of labor and the marginal rate of substitution between consumption and leisure.

Previous estimates of the elasticity of substitution between time and market goods using micro data typically rely on cross-sectional household variation for identification. We contribute to the literature in two ways. First, we estimate the elasticity by exploiting the variation over the recession period, in addition to variation across household demographic groups. The panel dimension of the data helps us in two ways. It allows us to control for unobserved, time-invariant household heterogeneity with household-group fixed effects, which could bias the estimates of the home production parameters. Moreover, we can allow for variation in returns to non-market work (and therefore opportunity cost of time) across households and time. Our second contribution is to use the time variation in the data to test whether home production shocks were important drivers of the joint variation in time spent on non-market work and expenditure on market goods observed during the recent recession.

\footnotetext{
${ }^{17}$ Models that explain the joint variation in aggregate variables based on the inclusion of a home production sector include Benhabib, Rogerson and Wright (1991), Baxter and Jermann (1999), Chang and Schorfheide (2003), Greenwood and Hercowitz (1991), and Rupert, Rogerson and Wright (1995).
} 
We restrict our home production function to have a constant elasticity of substitution between time and market goods:

$$
c_{t}=K\left(h_{t}, Q_{t}\right) \equiv\left(\phi h_{t}^{\rho}+Q_{t}^{\rho}\right)^{1 / \rho}
$$

for some positive constant $\phi$. This specification of a constant elasticity of substitution between time spent on home production. $h_{t}$, and market goods. $Q_{t}$, is commonly used in existing studies, and therefore adopting this form allows us to compare our results to previous estimates in the literature. The elasticity of substitution between $h_{t}$ and $Q_{t}$ is given by $\sigma \equiv 1 /(1-\rho)$, and the marginal rate of transformation (MRT) is given by

$$
\operatorname{MRT}=\frac{\partial K_{t} / \partial h_{t}}{\partial K_{t} / \partial Q_{t}}=\phi\left(\frac{h_{t}}{Q_{t}}\right)^{\rho-1}
$$

Substituting in equation (11) and taking logs, we have

$$
\ln \left(\frac{h_{t}}{Q_{t}}\right)=\sigma \ln (\phi)-\sigma z_{t}
$$

where $z_{t}=\ln \left(-\frac{\partial \ln p_{t}}{\partial s_{t}} Q_{t}\right)-\ln \left(\frac{\partial \ln p_{t}}{\partial \ln Q_{t}}+1\right)$.

The Homescan data do not have information on time spent on home production and shopping. Therefore, to estimate equation (19), we combine data on from the American Time Use Survey (ATUS) with the Homescan price and quantity data based on the household's age, gender, and marital status. We split the sample into two non-overlapping periods, $\mathrm{t}=1$ (year 2004-2007) and t=2 (years 2008-2010), to examine the change over the recession period. The time use, quantity, and price data are averaged across households and time within each household demographic group-time period. To compute the second term in equation (19) we combine information from Homescan on $Q$, with our estimates of the returns to shopping (Table 2 , column III), and an estimate of the price elasticity $\partial \ln p / \partial \ln Q .{ }^{18}$

We estimate equation (19) based on the following regression:

\footnotetext{
${ }^{18}$ The price elasticity $\partial \ln p_{j t} / \partial \ln Q_{j t}$ is estimated from the following regression

$$
\ln p_{j m}=\alpha_{0}+\alpha_{Q 1} \ln Q_{j m}+\alpha_{Q 2} \ln Q_{j t} \cdot 1(\text { year }>2007)+\alpha_{3} 1(\text { year }>2007)+\sum_{i} \delta_{i} f_{i j m}+\lambda_{j}+\nu_{j m}
$$
}

for household $j$ in month $m$. The price elasticity $\partial \ln p_{j t} / \partial \ln Q_{j t}$ therefore equals $\alpha_{Q 1}$ for $\mathrm{t}=1$, and $\alpha_{Q 1}+\alpha_{Q 2}$ for $t=2$. 


$$
\ln \left(\frac{h_{j t}}{Q_{j t}}\right)=\beta_{0}+\beta_{1} z_{t}+\beta_{2} z_{t} \cdot \lambda_{t}+\lambda_{j}+\lambda_{t}+\epsilon_{j t}
$$

for household-group $j$ (defined based on age, gender, and marital status) in period $t$. We control for household-group fixed effects using $\lambda_{j}$, and time fixed effects using $\lambda_{t}$ (which is an indicator variable equal to one for $t=2$ ). The estimate for the elasticity of substitution between home production time and market goods is given by the coefficient $-\beta_{1}=\sigma$, and the home production parameter $\phi$ is recovered from $\beta_{0}=\sigma \ln (\phi)$. We test for changes in $\sigma$ over the business cycle based on $\beta_{2}$. A significant $\beta_{2}$ would imply the existence of shocks to home production during the recession.

Column I in Table 4 gives the between-household estimate, where the identification of the coefficient comes from variation across household demographic groups. The elasticity of substitution between market goods and time spent on home production is estimated to be 1.2 , with a standard error of 0.39 . One concern with this estimate is that there may be unobserved heterogeneity within each household demographic group, which may bias the estimate of the elasticity. Therefore, we re-estimate equation (20), controlling for householdgroup fixed effects and allowing for variation across both household-group and time. This gives a higher elasticity of 1.7 , with a standard error of 0.48 (column II).

Our elasticity estimate of 1.7 is consistent with other micro and macro estimates of the elasticity. ${ }^{19}$ The estimates are supportive of business cycle models with a strong degree of complementarity between leisure and consumption, and home production models that assume a high elasticity of substitution between the market sector and non-market sector. In these models, home production amplifies the volatility of market work and consumption relative to output, and lowers the correlation between productivity and market work (see for example Benhabib, Rogerson and Wright (1991) and Greenwood and Hercowitz (1991)).

Our results also relate to recent studies that seek to explain the gap between the marginal product of labor and the marginal rate of substitution between consumption and leisure (known as the "labor wedge"), which widens during recessions. ${ }^{20}$ One hypothesis for the

\footnotetext{
${ }^{19}$ For example, Rupert, Rogerson and Wright (1995) use aggregate U.S. data to estimate an estimate that is slightly less than 2, while Chang and Schorfheide (2003) estimate a value of 2.3. Using micro data, estimates of 1.8-2.0 are estimated in studies including Rupert, Rogerson and Wright (1995) and Aguiar and Hurst (2007).

${ }^{20}$ Studies that have discussed the labor wedge include Karabarbounis (2014), Hall (1997), Shimer (2009), Cole and Ohanian (2004), Chari, Kehoe and McGrattan (2007), Chang and Kim (2007), and others.
} 
cyclical wedge is that it reflects the unaccounted for substitution of time between the market sector and the home sector in models without home production. This omission affects the measured rate of substitution between consumption and leisure, and therefore the measured labor wedge. Karabarbounis (2014) shows volatility of the labor wedge over the business cycle can be explained by a home production model that assumes a value of 4 for the elasticity of substitution between the market sector and the home sector. Our point estimate of 1.7 for the elasticity implies that the inclusion of a home production sector in these models may explain almost half of the measured labor wedge.

Our estimates also allow us to examine a second question: whether home production shocks are important drivers of the joint fluctuations between expenditure on market goods and time spent on non-market work during 2008-2010. We find a statistically and economically insignificant coefficient $\left(\beta_{2}\right)$ on the interaction term from equation (20) in our fixed-effects estimates (Table 4, column II). This result implies that home production shocks were not the driving force behind the decline in market expenditure and increase in time spent on non-market work between 2008 and 2010. This is consistent with Aguiar, Hurst and Karabarbounis (2013), who derive a similar conclusion using data on state-level unemployment rates and time use.

\subsection{Implications for Consumption Smoothing}

Our estimated home production function also allows us to describe how households smooth consumption over the business cycle. If households can substitute between expenditure and time, then during recessions they can smooth part of income and wealth shocks by reallocating time towards non-market work from time spent on leisure and market work. The idea that households can smooth consumption by changing their behavior is not new. For example, Blundell, Pistaferri and Saporta-Eksten (2012) show that households can partially smooth consumption when a member of the family becomes unemployed by increasing the hours worked by the secondary head of household. Here we consider a different margin of time allocation within a household: the intra-temporal allocation between market hours and non-market work. This is relevant for understanding the ability of households to smooth unanticipated income and wealth shocks over the business cycle. We now show how the changes in household behavior, we showed above, translate to variation in consumption relative to market expenditure using our estimated home production function. 
Table 4: Elasticity of Substitution in Home Production

Coefficient Interpretation

\begin{tabular}{lccc}
\hline & & & \\
$-\beta_{1}$ & $\begin{array}{l}\sigma \text { (elasticity of substitution between time } \\
\text { and goods in home production) }\end{array}$ & 1.205 & 1.708 \\
& & $(0.389)$ & $(0.481)$ \\
$-\beta_{2}$ & & 0.024 \\
& & $(0.080)$ \\
\hline & & \\
Estimation & Between-effects & Fixed-effects \\
Additional controls & Marital status & None \\
Number of groups & 27 & 54 \\
\hline
\end{tabular}

Note: This table reports the estimates of the elasticity of substitution between time and goods in home production. Columns 1 and 2 refer to coefficients estimated from equation (20), a regression of $\ln (h / Q)$ on price elasticities. American Time Use Survey and Homescan data are merged using 27 demographic period cells, based on age, sex, and marital status, for each year. Regressions are performed on cell averages across the demographic group within each period (2004-2007, and 2008-2010). Standard errors are in paratheses. See text for additional details. 
To see how consumption changed over 2008-2010, we take the derivative of the home production function (equation 17), and use a hat symbol to denote percentage change (relative to previous two-year period 2006-2007). The percentage change in consumption is given by

$$
\hat{C}=\theta \hat{h}+(1-\theta) \hat{Q}
$$

where

$$
\theta \equiv \frac{\phi h^{\rho}}{\phi h^{\rho}+Q^{\rho}}
$$

As in Aguiar and Hurst (2007), we can decompose the change in consumption during the recession relative to expenditure into home production substitution and price savings from shopping. ${ }^{21}$ Specifically, we can rewrite equation (21) as

$$
\hat{C}-\hat{X}=\theta(\hat{h}-\hat{X})-(1-\theta) \hat{p}
$$

where percentage change in expenditure on market goods is denoted by $\hat{X}=\hat{p}+\hat{Q} \cdot{ }^{22}$ The decomposition in equation (23) shows that households can smooth consumption by intratemporally reallocating time. The first term, $(\hat{h}-\hat{Q})$, reflects the substitution between time spent on home production and market goods. The second term, $\hat{p}$, gives the price savings derived from the change in shopping behavior during the recession.

We empirically compute the corresponding terms of equation (23) for the two distinct periods of 2006-07 and 2008-10. Specifically, for each of the two time periods, we calculate each term on the right hand side of (23) using the observed household averages for $h$ (from the American Time Use Survey), $Q$ and $X$ (from Homescan data), together with our estimates of $\rho$ and $\phi$ (from Section 5.2) and price savings (estimated using Homescan data and shown in Section 4). The average price savings across households and shopping activities is computed as $\hat{p} \equiv \sum_{i} \hat{f}_{i} \cdot\left(\partial \ln p / \partial f_{i}\right)$, where $\hat{f}_{i}$ denotes the increase in fraction of items with each shopping activity $i$ (coupon usage, purchases of sale, purchases of large items, purchases of generic products, and buying from Big Box stores), and $\partial \ln p / \partial f_{i}$ denotes the sensitivity of

\footnotetext{
${ }^{21}$ This decomposition was also taken in Aguiar and Hurst (2007), where they focused on the variation across households by age. Here, we shift the focus to the variation that occurred during the Great Recession period to understand the ability of households to further smooth consumption beyond market expenditure by varying their time use.

${ }^{22}$ The expenditure is deflated by an aggregate inflation index for food so that $\hat{X}$ excludes overall shifts in food prices, but includes changes in prices that were due to shifts in households shopping behavior (documented in Section 3) denoted by $\hat{p}$.
} 
price to the shopping activity, estimated in Section 4 (Table 2, column II). The parameter $\theta$ is computed based on equation (22) using the average $h$ and $Q$ over period $t=1$ (years 2006 and 2007), combined with our estimates of the home production parameter for $\rho$. This gives a value of 0.35 for $\theta$.

Table 5 shows the decomposition of the change in consumption relative to market expenditure, based on an estimated $\theta$ of 0.35 . Over the recession period, expenditure fell by 8.8 percent $(\hat{X})$, comprised of a 7.7 percent decline in quantity and a 1.1 percent decrease in prices paid due to increased shopping intensity. In contrast, consumption is measured to have declined by only 3.6 percent, which is about 60 percent less than the decline in market expenditure. As a result, the gap between consumption and market expenditure widened by 5.2 percent $(\hat{C}-\hat{X})$. Approximately 80 percent of the gap was due to a substitution from market goods towards time spent on home production (which rose by 3.8 percent), while increased shopping intensity accounted for the remaining 20 percent. $^{23}$

These results from our estimated home production function highlight the importance of intra-temporal variations in time use for the purposes of smoothing consumption. During recessions, households are faced with lower income and/or declines in wealth, which results in lower expenditure. By reallocating time from lost market hours and leisure towards nonmarket work, they are able to partially smooth the decline in consumption (relative to market expenditure). The results imply that intra-temporal reallocation of time reduced the decline in consumption by almost 60 percent during the recession. These facts are consistent with the observed joint decline in household expenditure and labor hours during recessions.

It is worth noting that our results pertain to food expenditures. Nonetheless, the ability to shop for bargains and utilize other means of home production can also apply to broader classes of goods. We expect that the ability to substitute between time and market expenditure can also play an important role in smoothing various non-food household consumption when households are faced with unanticipated income and wealth shocks.

\footnotetext{
${ }^{23}$ The share of the wedge $(\hat{C}-\hat{X})$ accounted for by the substitution between market goods and time spent on home production is calculated by $\theta(\hat{h}-\hat{Q}) /(\hat{C}-\hat{X})$. The share accounted for by lower prices due to increased shopping time is given by $-(1-\theta) \hat{p} /(\hat{C}-\hat{X})$.
} 
Table 5: Percentage change over 2008-2010, relative to 2006-2007

$\hat{X}$

(I) $\hat{p}$

(II)
$\hat{Q}$

(III) $\hat{h}$

(IV)
$\hat{C}$

(V)

Percentage change during the recession period $\quad \begin{array}{llllll}-8.83 & -1.13 & -7.70 & 3.77 & -3.65\end{array}$

Note: This table reports the percentage changes from 2008-2010 relative to 2006-2007 in market expenditure (computed from $\hat{p}+\hat{Q}$ ), price paid (using from results from Section 4, Table 2), quantity of market goods purchased (computed using the Homescan data), home production time (computed using data from the American Time Use Survey), and consumption (computed from equation (21) using data from Homescan and the American Time Use Survey, combined with the estimated parameters of the home production function from Section 5.2, Table 4). See text for more detail on the computation.

\section{Robustness}

In this section, we show that the main results of the previous section are qualitatively robust to alternative sample period and functional form specifications.

We first consider the sensitivity of our results to the inclusion of the 2007 in the estimation. This was a year with significant food price increases, due to increased demand in China and a drought in Australia, which were arguably unrelated to the business cycle. Excluding 2007 does not qualitatively change the finding that households' marginal value of time fell during the recession. Specifically, we find that the cost of time declined by 28 percent, compared with a decline of 30 percent when 2007 is included (Column II of Table 6 and Column I of Table 7 in the appendix). The estimated elasticity of substitution between market spending and time spent on home production is smaller in magnitude when 2007 is excluded (0.965 compared with 1.7), but the difference is statistically insignificant. As in our main results, we find that consumption declined by less than market expenditure over 2008-2010.

Next, in Column (III), we study whether the results change if we adjust for changes in quality associated with shifts in shopping behavior. ${ }^{24}$ To do so, we consider an alternative price index that takes into account changes in quality associated with the shifts from non-

\footnotetext{
${ }^{24}$ For example, Bils (2009) and Bils and Klenow (2001) show that measured inflation may be biased if product quality improvements are not taken into account.
} 
generic to generic products. The index is constructed using the methodology described in Section 4, but allows for two different average prices paid in each month: one for generic products, and one for non-generic products. The estimated returns to shopping from this alternative price index (column II of Table 7 in the appendix) are slightly lower than our base case returns (column III, Table 2). However, we still find that returns to each shopping activity declined during the recession period (column III of Table 6), implying a decline in cost of time that is comparable to our base results. The estimated elasticity of substitution between market spending and time spent on home production is comparable to our base result, and again imply that consumption declined by significantly less than market expenditure over 2008-10.

Lastly, we also explored the sensitivity of our results to our assumption on the relationship between shopping activity and shopping time. In Section 5.1-5.2, we computed the opportunity cost of time and estimated the home production parameters assuming that

$$
\partial f_{i t} / \partial s_{t}=\gamma_{i} / f_{i t}
$$

where $f_{i t}$ denotes the fraction of shopping activity $i$ as a share of total items bought by the household in month $t, s_{t}$ denotes the shopping time, and $\gamma_{i}$ is a constant term. We consider a range of alternative Box-Cox functional forms for $f(s)$ with varying $\lambda$ :

$$
f(s)=\left(s^{\lambda}-1\right) / \lambda
$$

In columns (IV-VI) of Table 6 , we present the results for the cases $\lambda=-1, \lambda=0$ (i.e. $f(s)=\log (s)$ ), and $\lambda=1$. We find that the decline opportunity cost of time is qualitatively robust across the various Box-Cox functional forms, with the change decreasing in the size of $\lambda$. Similarly, we estimate a high elasticity of substitution between home production time and market spending, which rises in $\lambda$, and a widening of the gap between implied consumption and measured market spending during the Great Recession.

In summary, we find that our results are qualitatively robust to alternative sample periods and functional form specifications: we find lower returns to shopping during the recession, a sizable reduction in opportunity cost of time, and significant elasticity of substitution between home production and market expenditure. These estimates imply that consumption declined by less than market expenditure during the recession, in part because households lowered the price they paid and engaged more in home production. 
Table 6: Robustness Results under Varying Assumptions

\begin{tabular}{cccccc} 
Base Results & Excluding & Alternative & \multicolumn{3}{c}{ Box-cox form for $f(s)$} \\
& Year 2007 & Price Index & $\lambda=-1$ & $\lambda=0$ & $\lambda=1$ \\
(I) & (II) & (III) & (IV) & (V) & (VI)
\end{tabular}

\section{Robustness for Section $\mathbf{5 . 1}$}

$\begin{array}{lllllll}\text { Change in cost of time: } & -0.297 & -0.281 & -0.237 & -0.216 & -0.201 & -0.191 \\ & (0.058) & (0.043) & (0.07) & (0.075) & (0.077) & (0.079)\end{array}$

\section{Robustness for Section $\mathbf{5 . 2}$}

Elasticity of substitution:

$\begin{array}{ccccccc}\sigma & 1.708 & 0.965 & 1.64 & 1.553 & 1.655 & 1.709 \\ & (0.481) & (0.356) & (0.498) & (0.38) & (0.399) & (0.413) \\ \sigma \cdot 1 \text { (recession) } & & & & & & \\ & 0.024 & -0.05 & -0.027 & 0.002 & 0.004 & 0.004 \\ & (0.080) & (0.076) & (0.081) & (0.06) & (0.063) & (0.065)\end{array}$

\section{Robustness for Section $\mathbf{5 . 3}$}

Consumption decomposition (percent change over 2008/10):

$\begin{array}{lcccccc}\hat{X} \text { (market expenditure) } & -8.83 & -5.88 & -8.61 & -8.83 & -8.83 & -8.83 \\ \hat{p} \text { (price) } & -1.13 & -1.28 & -0.69 & -1.13 & -1.13 & -1.13 \\ \hat{Q} \text { (quantity) } & -7.70 & -4.60 & -7.92 & -7.70 & -7.70 & -7.70 \\ \hat{h} \text { (home production time) } & 3.77 & 3.97 & 3.77 & 3.77 & 3.77 & 3.77 \\ \hat{C} \text { (consumption) } & -3.65 & -1.53 & -3.80 & -2.96 & -3.78 & -4.35 \\ \hat{C}-\hat{X} & 5.18 & 4.35 & 4.82 & 5.87 & 5.05 & 4.48\end{array}$

Note: This table gives the results under various robustness checks. Column (I) reproduces the base results from Section 5, based on price index II. Columns (II)-(VI) show the results under alternative assumptions: (II) excludes year 2007, (III) uses an alternative price index which controls for the decline in quality due to the switch from non-generic to generic products, (IV)-(VI) assume varying Box-Cox functional forms for $f=\left(s^{\lambda}-1\right) / \lambda$. Standard errors are given in parentheses. See text for more details. 


\section{Conclusion}

In this paper, we study how households substitute between time and money during the recent recession, and compute the implications for consumption smoothing. We find that households increased time spent on home production and shopping to reduce their market expenditure, in a manner that is consistent with lower cost of time during the recession. Our findings are consistent with theoretical home production models, which predict positive co-movement between labor hours and expenditure.

Specifically, using Homescan data from Nielsen, we document that during the recent recession, households increased their shopping intensity by purchasing more on sale, using more coupons, buying larger sizes, switching to generic products and shopping more at Big Box stores. These activities allowed households to lower the prices paid. However, we also find that the returns to shopping declined during the recession. The lower returns imply a sizable decline in households' opportunity cost of time of 25-30 percent over 2008-2010. The change in opportunity cost of time is consistent with a high elasticity of substitution between market goods and time in home production, indicative of a high degree of complementarity between leisure and consumption. We find households were able to smooth a sizable portion of their consumption during recessions by varying their intra-temporal allocation of time. 


\section{References}

Aguiar, Mark, and Erik Hurst. 2007. "Life-cycle Prices and Production." American Economic Review, 5(3): 1533-1599.

Aguiar, Mark, Erik Hurst, and Loukas Karabarbounis. 2013. "Time Use during the Great Recession." American Economic Review, 103(5): 1664-1696.

Baxter, Marianne, and Urban J. Jermann. 1999. "Household Production and the Excess Sensitivity of Consumption to Current Income." American Economic Review, 89(4): 902-920.

Becker, Gary. 1965. "A Theory of the Allocation of Time." Economic Journal, 75(299): 493-508.

Benhabib, Jess, Richard Rogerson, and Randall Wright. 1991. "Homework in macroeconomics: Household production and aggregate fluctuations." Journal of Political economy, 99(6): 1166-1187.

Beraja, Martin, Erik Hurst, and Juan Ospina. 2015. "The Aggregate Implications of Regional Business Cycles."

Bils, Mark. 2009. "Do Higher Prices for New Goods Reflect Quality Growth or Inflation?" The Quarterly Journal of Economics, 124(2): 637-675.

Bils, Mark, and Peter J. Klenow. 2001. "Quantifying Quality Growth." American Economic Review, 91(4): 1006-1030.

Blundell, Richard, Luigi Pistaferri, and Itay Saporta-Eksten. 2012. "Consumption inequality and family labor supply." National Bureau of Economic Research.

Chang, Yongsung, and Frank Schorfheide. 2003. "Labor-supply shifts and economic fluctuations." Journal of Monetary Economics, 50(8): 1751-1768.

Chang, Yongsung, and Sun-Bin Kim. 2007. "Heterogeneity and aggregation: Implications for labor-market fluctuations." The American Economic Review, 97(5): 1939-1956.

Chari, Varadarajan V, Patrick J Kehoe, and Ellen R McGrattan. 2007. "Business cycle accounting." Econometrica, 75(3): 781-836. 
Chevalier, Judith A, and Anil K Kashyap. 2011. "Best prices." National Bureau of Economic Research.

Coibion, Olivier, Yuriy Gorodnichenko, and Gee Hee Hong. 2012. "The cyclicality of sales, regular and effective prices: Business cycle and policy implications." National Bureau of Economic Research.

Cole, Harold L, and Lee E Ohanian. 2004. "New Deal policies and the persistence of the Great Depression: A general equilibrium analysis." Journal of Political Economy, 112(4): 779-816.

Einav, Liran, Ephraim Leibtag, and Aviv Nevo. 2010. "Recording discrepancies in Nielsen Homescan data: Are they present and do they matter?" Quantitative Marketing and Economics, 8(2): 207-239.

Greenwood, Jeremy, and Zvi Hercowitz. 1991. "The allocation of capital and time over the business cycle." Journal of Political Economy, 99(6): 1188-1214.

Griffith, Rachel, Ephraim Leibtag, Andrew Leicester, and Aviv Nevo. 2009. "Consumer Shopping Behavior: How Much Do Consumers Save?" Journal of Economic Perspectives, 23(2): 99-120.

Griffith, Rachel, Martin OConnell, and Kate Smith. 2014. "Partial consumption smoothing over the Great Recession."

Hall, Robert E. 1997. "Macroeconomic Fluctuations and the Allocation of Time." Journal of Labor Economics, 15(1): 223-250.

Heathcote, Jonathan, Kjetil Storesletten, and Giovanni L Violante. 2009. "Quantitative macroeconomics with heterogeneous households." Annual Review of Economics, 1: $319-354$.

Kaplan, Greg. 2012. "Moving back home: Insurance against labor market risk." Journal of Political Economy, 120(3): 446-512.

Kaplan, Greg, and Guido Menzio. 2013. "Shopping externalities and self-fulfilling unemployment fluctuations." National Bureau of Economic Research.

Kaplan, Greg, and Guido Menzio. 2014. "The morphology of price dispersion." National Bureau of Economic Research. 
Karabarbounis, Loukas. 2014. "Home production, labor wedges, and international real business cycles." Journal of Monetary Economics, 64: 68-84.

Mian, Atif, and Amir Sufi. 2010. "Household Leverage and the Recession of 2007-09." IMF Economic Review, 58(1): 74-117.

Rupert, Peter, Richard Rogerson, and Randall Wright. 1995. "Estimating substitution elasticities in household production models." Economic Theory, 6(1): 179-193.

Shapiro, Matthew D, and David W Wilcox. 1996. "Mismeasurement in the Consumer Price Index: An Evaluation.” NBER Macroeconomics Annual 1996, 11: 93-154.

Shimer, Robert. 2009. "Convergence in Macroeconomics: The Labor Wedge." American Economic Journal: Macroeconomics, 1(1): 280-297.

Stroebel, Johannes, and Joseph Vavra. 2015. "House Prices, Local Demand, and Retail Prices." SSRN. 


\section{A Online Appendix: Additional Results}

\section{A.1 Additional Figures of Shopping Activity}
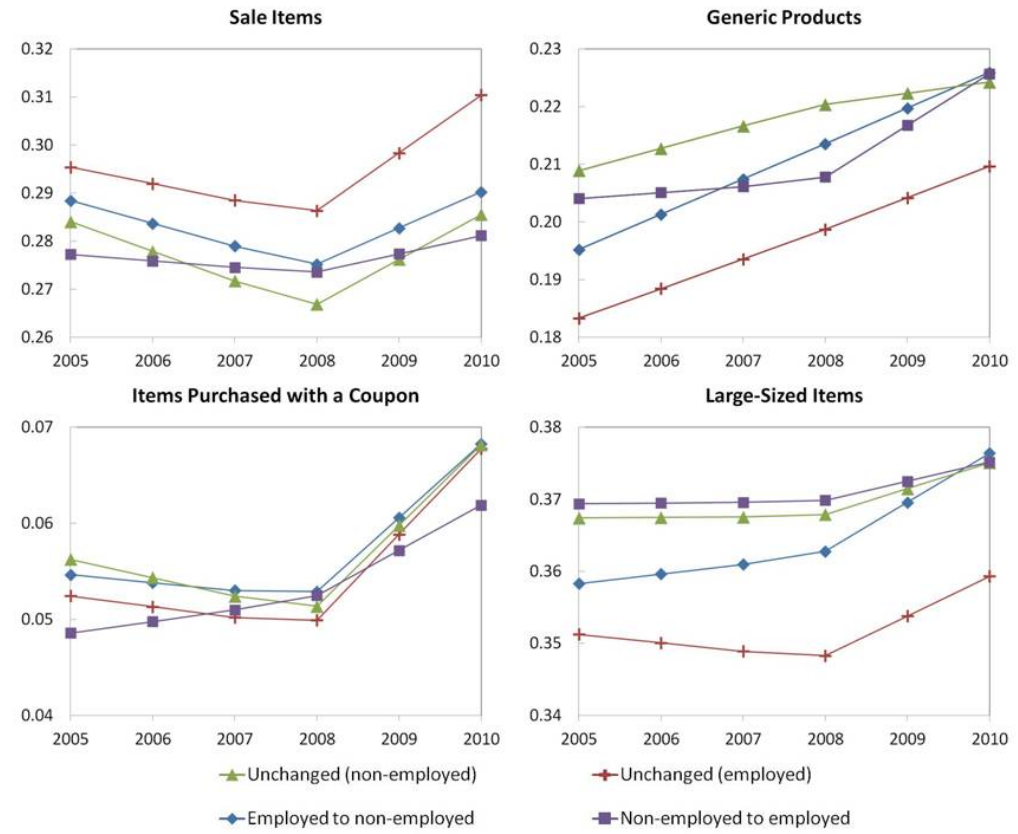

Figure 6: Behavior by employment transitions (Share of total household expenditure)
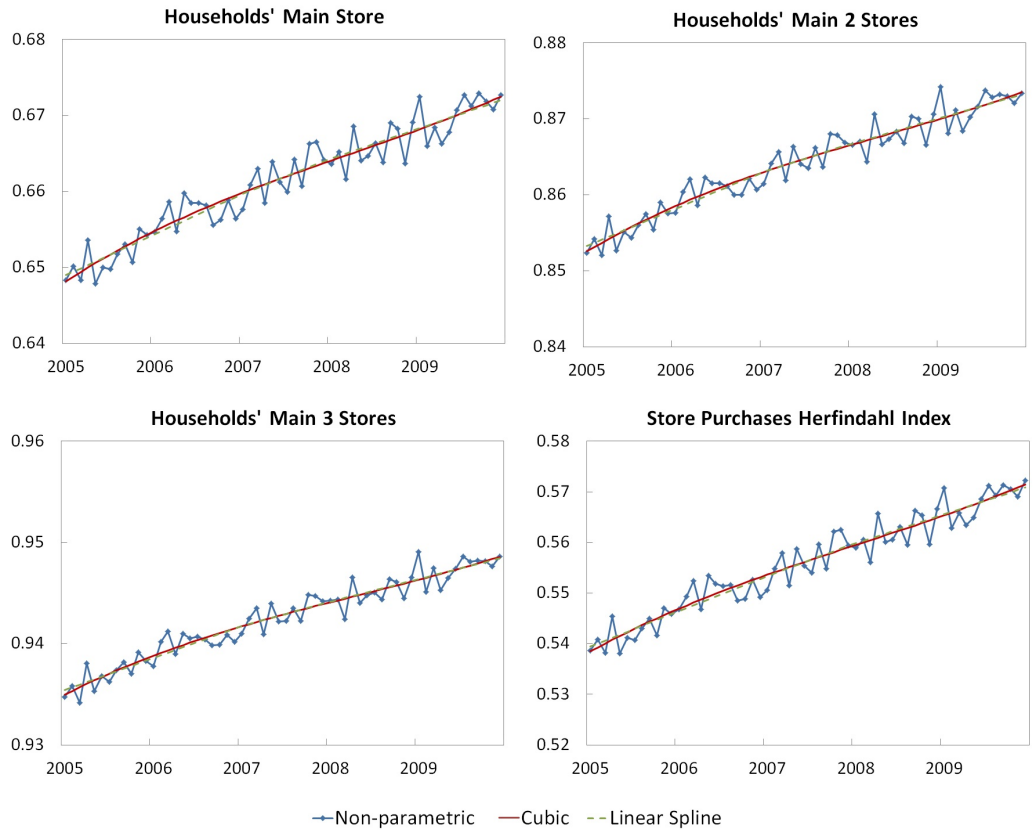

Figure 7: Concentration of expenditure by store (Share of total household expenditure) 


\section{A.2 Returns to Shopping}

In this section, we consider three robustness checks to our returns to shopping analysis. First, we consider the sample period. Second, we consider yet another definition of a product to control for quality differences in purchases. Third, we consider the robustness of our analysis to the definition of a market used to compute the comparison average price paid by all households within the defined market. We find our results are qualitatively robust to all three robustness checks.

Table 7 gives the estimated returns to shopping under two different robustness checks. In Column (I), we estimate the returns excluding the year 2007. In Column (II), we estimate the returns using an alternative price index (described in the main text) which controls for the decline in quality due to a shift from non-generic to generic products. 
Lastly, we also consider the robustness of our results to the definition of a market used for computing the comparison average price paid in the market. Specifically, we compute returns using a price index with the comparison average market price computed at a county level instead of at a national level. Table 8 gives the estimated returns to shopping based on an alternative price index:

$$
\tilde{p}_{m}^{h} \equiv \frac{\sum_{J \in \mathbf{D}} \sum_{j \in \mathbf{J}, t \in m} p_{j, t}^{h} q_{j, t}^{h}}{\sum_{J \in \mathbf{D}} \sum_{j \in \mathbf{J}, t \in m} \bar{p}_{j, m} q_{j, t}^{h}}
$$

for household $h$ in month $m$. As described in the text earlier, $J$ denotes a product, $D$ denotes the set of all products, and $q$ are household-level quantities. In this alternative index, we vary the definition of a market when defining the "average" comparison price in the market $\bar{p}_{j, m}$. Specifically, we consider defining a market at a county level, rather than at a national level.

The advantage of using a county definition of a market is that it allows us to control for any possible county-specific supply shocks that are common across households within that same county. Recall that the index controls for common supply-side shifts because these factors are reflected in both the household-specific expenditure (the numerator) as well as the comparison expenditure at average market prices (the denominator). Thus supply-side shifts over time that are common across households within the same market are netted out in the price index.

A disadvantage, however, of using a county-level definition of a market rather that a nation-wide definition (considered in the main body of the text) is that we now need to restrict the sample to counties that have sufficient number of panelists in the data to construct a representative relative price index. Specifically, we restrict the sample to consist only of counties that have at least 1,000 sample households. This reduces the sample by just over 40 percent to 2.3 million households.

Based on this sub-sample of counties, we find qualitatively similar results to our main results. That is, we find that returns to shopping declined during the recession period for all main shopping activities. 
Table 7: Robustness of Returns to Shopping

\begin{tabular}{|c|c|c|}
\hline & $\begin{array}{c}\text { Exclude } 2007 \\
\text { (I) }\end{array}$ & $\begin{array}{l}\text { Alternative Price Index } \\
\text { (II) }\end{array}$ \\
\hline Sale & $\begin{array}{c}-3.7^{* * *} \\
(0.36)\end{array}$ & $\begin{array}{c}-6.5^{* * *} \\
(0.34)\end{array}$ \\
\hline Coupon & $\begin{array}{c}-29.4^{* * *} \\
(0.69)\end{array}$ & $\begin{array}{c}-25.9^{* * *} \\
(0.61)\end{array}$ \\
\hline Big box & $\begin{array}{c}-11.3^{* * *} \\
(0.24)\end{array}$ & $\begin{array}{c}-9.4^{* * *} \\
(0.2)\end{array}$ \\
\hline Generic & $\begin{array}{c}-25.9^{* * *} \\
(0.4)\end{array}$ & $\begin{array}{c}4.7^{* * *} \\
(0.35)\end{array}$ \\
\hline Large sizes & $\begin{array}{c}-45.6^{* * *} \\
(0.4)\end{array}$ & $\begin{array}{c}-44.9^{* * *} \\
(0.34)\end{array}$ \\
\hline Sale $\cdot 1(\mathrm{yr}>2007)$ & $\begin{array}{l}1.2^{* * *} \\
(0.34)\end{array}$ & $\begin{array}{l}2.4^{* * *} \\
(0.26)\end{array}$ \\
\hline Coupon $\cdot 1(y r>2007)$ & $\begin{array}{l}2.9^{* * *} \\
(0.72)\end{array}$ & $\begin{array}{l}1.1^{* * *} \\
(0.57)\end{array}$ \\
\hline Big box $1(y r>2007)$ & $\begin{array}{l}2.7^{* * *} \\
(0.26)\end{array}$ & $\begin{array}{l}1.4^{* * *} \\
(0.21)\end{array}$ \\
\hline Generic $\cdot 1(y r>2007)$ & $\begin{array}{l}2.8^{* * *} \\
(0.44)\end{array}$ & $\begin{array}{l}0.5^{* * *} \\
(0.37)\end{array}$ \\
\hline Large sizes $1(\mathrm{yr}>2007)$ & $\begin{array}{l}2.3^{* * *} \\
(0.48)\end{array}$ & $\begin{array}{l}2.1^{* * *} \\
(0.42)\end{array}$ \\
\hline Product definition & $\mathrm{PM}$ & $\mathrm{PM}$ \\
\hline Market definition & U.S. & U.S. \\
\hline Index quantity weights & Household-specific & Household-specific \\
\hline
\end{tabular}

Note: Estimates in column (I) are based on a sample over the year 2004-2006 and 2008-2010 (i.e. it excludes 2007). The estimates are used to compute the results in Table 6, column (II). Estimates in column (II) are based on an alternative price index which controls for the decline in quality due to a shift from non-generic to generic products. The estimates are used to compute the results in Table 6, column (III). Standard errors are given in parentheses. ${ }^{* * *},{ }^{* *},{ }^{*}$ denote significance at a 1,5 , and 10 percent level, respectively. 
Table 8: Estimated Returns to Shopping: County-level Regressions

\begin{tabular}{|c|c|c|c|}
\hline Variable & (I) & (II) & (III) \\
\hline \multirow[t]{2}{*}{ Sale } & $-4.2^{* * *}$ & $-2.01^{* * *}$ & $-3.41^{* * *}$ \\
\hline & $(0.06)$ & $(0.09)$ & $(0.11)$ \\
\hline \multirow[t]{2}{*}{ Coupon } & $-36.7^{* * *}$ & $-34.3^{* * *}$ & $-32.5^{* * *}$ \\
\hline & $(0.13)$ & $(0.18)$ & $(0.22)$ \\
\hline \multirow[t]{2}{*}{ Big Box } & $-8.48^{* * *}$ & $-9.23^{* * *}$ & $-12.1^{* * *}$ \\
\hline & $(0.05)$ & $(0.07)$ & $(0.08)$ \\
\hline \multirow[t]{2}{*}{ Generic } & $-0.19^{* *}$ & $-13.2^{* * *}$ & $-23.1^{* * *}$ \\
\hline & $(0.08)$ & $(0.12)$ & $(0.14)$ \\
\hline \multirow[t]{2}{*}{ Large size } & $0.88^{* * *}$ & $-20.5^{* * *}$ & $-46.9^{* * *}$ \\
\hline & $(0.08)$ & $(0.12)$ & $(0.14)$ \\
\hline \multirow[t]{2}{*}{ Sale $1(y r>2007)$} & $1.12^{* * *}$ & $0.66^{* * *}$ & $0.91^{* * *}$ \\
\hline & $(0.06)$ & $(0.09)$ & $(0.11)$ \\
\hline \multirow[t]{2}{*}{ Coupon 1(yr>2007) } & $0.8^{* * *}$ & $0.83^{* * *}$ & $1.1^{* * *}$ \\
\hline & $(0.13)$ & $(0.19)$ & $(0.23)$ \\
\hline \multirow[t]{2}{*}{ Big Box 1(yr>2007) } & $0.3^{* * *}$ & $1.4^{* * *}$ & $1.99^{* * *}$ \\
\hline & $(0.05)$ & $(0.08)$ & $(0.09)$ \\
\hline \multirow[t]{2}{*}{ Generic $1(y r>2007)$} & $-1.1^{* * *}$ & $0.85^{* * *}$ & $0.57^{* * *}$ \\
\hline & $(0.09)$ & $(0.13)$ & $(0.16)$ \\
\hline \multirow[t]{2}{*}{ Large Size 1(yr>2007) } & $-0.36^{* * *}$ & -0.19 & $1.18^{* * *}$ \\
\hline & $(0.11)$ & $(0.15)$ & $(0.18)$ \\
\hline Product definition & UPC & Features & $\mathrm{PM}$ \\
\hline Market definition & County & County & County \\
\hline Index quantity weights & Household-specific & Household-specific & Household-specific \\
\hline $\mathrm{N}$ & $2,302,817$ & $2,303,696$ & $2,304,106$ \\
\hline R-squared & 0.474 & 0.475 & 0.592 \\
\hline
\end{tabular}

Note: This table reports estimates of the regression estimates of equation (6) (quantity weighted), with different price indices in each column. Standard errors are in parentheses. ${ }^{* *},{ }^{* *},{ }^{*}$ denote significance at a 1, 5, and 10 percent level, respectively. (I) uses the $\log$ Price Index 1, where a product is as a UPC. (II) uses the $\log$ of Price Index 3, where a product consists of items that have the same characteristics (see text for more detail). (III) uses log of Price Index 2, where a product is defined at the product module. Each regression includes household and month fixed effects, and time-varying demographics. 